\title{
A Review of Neutrophil Extracellular Traps (NETs) in Disease: Potential Anti-NETs Therapeutics
}

\author{
Victoria Mutua ${ }^{1}$ (D) - Laurel J. Gershwin ${ }^{1}$ \\ Published online: 1 August 2020 \\ (C) Springer Science+Business Media, LLC, part of Springer Nature 2020
}

\begin{abstract}
Activated neutrophils release neutrophil extracellular traps (NETs) in response to a variety of stimuli. NETosis is driven by protein-arginine deiminase type 4 , with the release of intracellular granule components that function by capturing and destroying microbes, including viral, fungal, bacterial, and protozoal pathogens. The positive effects of pathogen control are countered by pro-inflammatory effects as demonstrated in a variety of diseases. Components of NETS are non-specific, and other than controlling microbes, they cause injury to surrounding tissue by themselves or by increasing the pro-inflammatory response. NETs can play a role in enhancement of the inflammation seen in autoimmune diseases including psoriasis, rheumatoid arthritis, and systemic lupus erythematosis. In addition, autoinflammatory diseases such as gout have been associated with NETosis. Inhibition of NETs may decrease the severity of many diseases improving survival. Herein, we describe NETosis in different diseases focusing on the detrimental effect of NETs and outline possible therapeutics that can be used to mitigate netosis. There is a need for more studies and clinical trials on these and other compounds that could prevent or destroy NETs, thereby decreasing damage to patients.
\end{abstract}

Keywords Neutrophil extracellular traps $\cdot$ NETs $\cdot$ Therapeutics $\cdot$ Anti-NETs $\cdot$ PAD4

\section{Introduction}

Neutrophil extracellular traps (NETs) were discovered in 1996 [1] and further detailed by Brinkmann et al. who termed the process NETosis [2-4]. Neutrophils are short-lived granulocytes that are the initial defense against invading pathogens. They achieve this through phagocytosis, degranulation, production of reactive oxygen species (ROS), and production of chemokines and cytokines to recruit other immune cells maximizing the host's immune response [5-7]. Neutrophils enhance their antimicrobial properties by releasing NETs, composed of extracellular chromatin decorated with histones and numerous granular proteins $[3,8]$ and were identified as part of innate immune response which can either be beneficial or pathological $[2,8,9]$. NET formation starts with the activation of neutrophils through the recognition of

Victoria Mutua

vnmutua@ucdavis.edu

1 Department of Pathology, Microbiology, and Immunology, School of Veterinary Medicine, University of California Davis, 1 Shields Ave, Davis, CA, USA stimuli and activation of NADPH oxidase (NOX) complex through protein kinase C (PKC)-Raf/MERK/ERK [9-11] which in turn activate myeloperoxidase (MPO), neutrophil elastase (NE), and protein-arginine deiminase type 4 (PAD4) $[12,13]$. PAD4 catalyzes citrullination of histones and promotes chromatin decondensation [14-16], while the ROS species promote NETosis by inducing gradual separation and loss of the nuclear membrane with the release of chromatin outside the cell through membrane pores. Cellular lysis with a final release of DNA, citrullinated histones (citH3), and other intracellular granules form the extracellular traps [10]. NETosis is induced in response to stimuli promoting pathogen clearance by trapping, and either killing through microbial toxicity or immobilizing microbes facilitating phagocytosis by other neutrophils and phagocytes $[3,15,17,18]$.

Due to the non-specific effects of the released enzymatic proteins, NETs may lead to uncontrolled inflammatory response causing tissue pathology. There is direct cell damage, recruitment of other pro-inflammatory cells and proteins, and formation of immune complexes that induce autoantibody production leading to tissue damage $[19,20]$. NETs can capture metastatic tumors aggravating cancerous condition [21], and in diabetic cases, they lead to a delay in wound healing $[22,23]$. Neutrophil can also form interactions with platelets 
mediated by P-selectin [24]. This leads to induction of platelet-derived high-mobility group protein B1 (HMGB1) [25] which stimulates NETs [24, 26] causing occlusion in the vasculature by promoting thrombosis and obstruction causing organ damage. Although NETs have been shown to promote inflammation, a study done by Christine et al. shows that an accumulation of NET aggregates can reduce inflammation in a mouse model of gout through the degeneration of cytokines and chemokines [27]. This means that there is still much about NETs we are not aware of, and thus the need for more studies to understand their specific mechanism and how to harness their benefits while limiting their negative effects.

There are certain compounds that have been identified in some studies to either inhibit or disrupt NETosis, but there is no available therapeutic that has been researched extensively or approved for human use. We propose that the limited therapeutics have been due to the different effects of NETs in different disease conditions; thus, identifying a stand-alone compound might be a challenge. In this review, we briefly mention NETosis in different diseases and try to reconcile different aspects of NET biology highlighting possible compounds that can be considered therapeutic. New approaches in therapeutic design and efficacy testing will have to be developed to find a truly efficacious treatment.

\section{Effects Of NETs}

Here is a brief discussion on the different researched effects of NETs.

\section{Antimicrobial}

NETs have been shown to have positive effects in controlling bacterial infections. They possess antimicrobial properties with components including histones, cathepsin G, NE, MPO, lactoferrin, antimicrobial peptide-LL37, pentraxin 3, gelatinase, proteinase 3 , and peptidoglycan-binding proteins that are bactericidal $[2,28,29]$. NETs limit growth or kill bacterial as reviewed by Vidal Delgado-Rizo et al. which include Shigella flexneri, Pseudomonas aeruginosa, Escherichia coli, Shigella sonnei, Salmonella enteritidis, Salmonella typhimurium, Klebsiella pneumoniae, Pseudomonas aeruginosa, Staphylococcus albus, Staphylococcus aureus, and Propionibacterium [8, 30].

In viral infections including influenza, HIV, and respiratory syncytial virus, there is an excessive neutrophil recruitment $[31,32]$. These viruses stimulate NETosis through TLR 4, 7 and/or 8 with the release of ROS species and the NETs trap, contain, and eliminate viruses [32-34] or inhibit viral replication through the blockade of the PKC pathway. Histones are also important for viral aggregation and neutralization leading to a significant decrease in viral replication $[35,36]$.
Fungi like Aspergillus nidulans, Candida albicans, Aspergillus fumigatus, and Cryptococcus spp. induce NETosis through the recognition of $\beta$-glucan on hyphae by components of the extracellular matrix or activation of NOX $[17,37,38]$. NETs have been shown to be important in trapping and clearing large pathogens in vivo, thus being critical for antifungal defense [17, 39, 40].

In parasitic conditions including Plasmodium falciparum and Toxoplasma gondii, there is activation of platelets, monocytes, and neutrophils. NET formation, which is dependent on MEK-ERK pathway, limits the dissemination of the parasites by trapping and killing them [41, 42]. Histones reduce the replication of the Leishmania spp. [43] and together with other NETs-associated compounds, such as NE, MPO, and collagenase, were shown to kill these pathogens [41-44].

Most studies on NETs have been done in mice and in vitro, but there is still a gap in knowledge on the exact mechanism of NETs in vivo. This necessitates the need for more studies to clearly evaluate their effects in in vivo and in humans.

\section{NETs as Biomarkers}

The ability to detect NETs may be used as a prognostic tool for patients with conditions presenting with a higher rate of NET formation, facilitating clinicians to provide personalized treatment. For NETs to be used as screening tools, there has to be studies to standardize and define normal from abnormal levels. This could involve measurement of NET-associated products in the blood cfDNA, citH3, NE, and MPO. In colorectal and breast cancer patients, cfDNA has been quantified in serum samples via a simple nucleic acid-staining assay [45-48]. This can be used to classify the cancer; however, measuring circulating $\mathrm{MPO} / \mathrm{cfDNA}$ conjugates and citH3 may be more specific for NET analysis than evaluation of cfDNA alone [49]. CitH3 is highly specific to NETosis making it a possible tool for understanding variances between NET levels [50]. Thalin observed that high plasma content of citH3 was a significant indicator of short-term mortality in some cancer patients [51], and some observational studies inform on the significance of NETs in progression of colorectal cancer [40]. Further human studies are needed to definitively quantify different levels of NETs and associate them with poor cancer/disease outcomes.

\section{Negative Effects of NETs}

Although NETs may protect the host against microbes, excessive NETosis can be detrimental to the host. Recent discoveries in in vitro experiments and animal models demonstrated the crucial role of NETs in the pathogenesis of some metabolic, autoimmune, and autoinflammatory diseases and certain septic conditions increasing morbidity and mortality. 


\section{Sepsis}

Large amounts of circulating NETs demonstrated in septic patients are associated with poor outcome and multiple organ failure $[50,52,53]$. This could be due to increased NETosis, apoptosis, and necrosis or decreased clearance of extruded products with studies suggesting that cfDNA exacerbate inflammation by inducing TNF- $\alpha$ mRNA $[54,55]$. Histones also function as damage-associated molecular patterns and can induce organ damage by promoting pro-inflammatory cytokine release causing endothelial dysfunction by inducing cytotoxicity and increasing ROS production $[53,56,57]$.

\section{Autoimmunity}

NETs have been indicated in pathologic alterations in autoimmune and autoinflammatory diseases $[58,59]$. Here, we discuss in brief a few of these diseases.

Psoriasis is a chronic immune-mediated disease characterized by demarcated erythematous plaques on the skin. Some patients may also suffer from psoriatic arthritis with joint pains and deformities [60-63]. Studies show that neutrophils are recruited to psoriasis lesions where they cluster to form spongiform pustules and Munro's microabscesses and produce pro-inflammatory cytokines including IL-6, IL-8, and IL-17s [60, 64]. IL-17 in keratinocytes increases the expression of LL37, a cathelicidin-derived antimicrobial peptide, and defensins which mediate NET formation in dermatological conditions $[30,65]$. These inflammatory compounds have been shown to promote NETosis and pathology in the absence of infection [59] in these patients.

Systemic lupus erythematosus (SLE) is an autoimmune disease characterized by immune complexes and high levels of IFN- $\alpha$ with the activation of autoreactive B cells $[66,67]$. There is a possible production of autoantibodies against nucleic acids released by neutrophils undergoing NETosis $[19,68]$ with the generated immune complexes representing a source of self-antigens that enhance the autoimmune and inflammatory process. This in turn results in more injury and inflammation [20,69].

Rheumatoid arthritis (RA) is a systemic autoimmune disease characterized by persistent synovial inflammation that leads to cartilage and bone injury in the joints [70]. The synovial fluid at the synovial cavity of RA patients becomes infiltrated with neutrophils that readily form NETs [71, 72]. Studies have demonstrated that circulating neutrophils of RA patients are more easily stimulated to NETosis than those from healthy subjects [73, 74], and as in other autoimmune conditions, NETs act as a source of extracellular autoantigens leading to excessive innate and adaptive immune responses in the joints and subsequent tissue injury $[73,75]$.

Type 1 diabetes mellitus (T1DM) is an autoimmune disease characterized by the destruction of $\beta$ pancreatic cells leading to hyperglycemia [76]. This causes production of autoantigens that are recognized by immune cells with production of autoantibodies $[30,58]$. T1DM patients are at a risk of developing neutropenia, and neutrophils can be found within infiltrates in pancreatic islets where elevated TNF- $\alpha$ induces formation of NETs [77]. Cytokines produced in this process lead to neutrophil recruitment to sites of inflammation, providing negative feedback and contributing to pathogenesis in autoimmune diabetes [58, 77].

Small vessel vasculitis (SVV) is a systemic disease of unknown etiology where the patients exhibit blood vessel inflammation, with necrotizing inflammation in small blood vessels potentially leading to organ damage [78-80]. These patients have been shown to have anti-neutrophil cytoplasmic antibodies (ANCAs) [7, 81]. Proteins released during NETosis are the main cause of ANCA production by activating the complement system resulting in endothelial damage $[81,82]$. These studies have shown that $\alpha$-PR3 and $\alpha$-MPO ANCAs induce NETosis during active disease perpetuating a feedback loop [81].

\section{Autoinflammatory Diseases}

Gout is an autoinflammatory disease characterized by the deposition of monosodium urate (MSU) crystals in the joints, stimulating immune responses by attracting leukocytes and inducing NETs that promote inflammation [27, 72, 83-85].

Inflammatory bowel diseases (IBDs) are disease affecting the gastrointestinal tract characterized by chronic uncontrolled inflammation. The two major forms of IBD include ulcerative colitis (UC) and Crohn's disease (CD), which have different etiologies, pathogenesis, and diagnostic features with the differences not fully understood. CD clinically manifests as gastrointestinal disorders but is a systemic disease involving inflammation of the ileum and colon [86-88]. NET formation in $\mathrm{CD}$ has not been well-studied although studies indicate that ROS production is enhanced, which could promote NETosis [30, 89-91]. UC is also characterized by inflammation of the gastrointestinal tract mostly restricted to the colon with NETs observed in the colon accompanied by exacerbated inflammation [64]. There are a few studies looking into the mechanism of NETs in these conditions, but there are more studies needed to better inform on development of effective treatment options.

\section{Metabolic Diseases}

Metabolic diseases have been associated with chronic lowgrade inflammation with activation of the innate immune response and recruitment of mononuclear and polymorphonuclear leukocytes increasing cellular dysfunction [92, 93]. This microenvironment favors NETosis linking it to immune 
deregulation and hyperglycemia, oxidative stress, inflammation, and further complications of metabolic diseases.

Type 2 diabetes is a chronic metabolic condition characterized by glucose level build-up in the bloodstream, hyperglycemia, and cells unresponsive to insulin. Studies have shown that hyperglycemia predisposes neutrophils to release NETs. NET-related bioproducts (NE, MPO, and cfDNA) are increased compared with non-diabetic subjects and also positively correlate with increased glycated hemoglobin (HbA1c) levels $[23,77]$. This suggests that the chronic proinflammatory conditions present during hyperglycemia promote NETosis in both the type 1 and type 2 diabetes [22, 94]; thus, NET formation is enhanced in hyperglycemic conditions independent of diabetes type and origin.

Obesity is a metabolic condition characterized by an excess of adipose tissue deposition, as a result of energy imbalance due to increased energy intake versus expenditure. Obesity is frequently associated with other chronic complications including cardiovascular disease and diabetes $[95,96]$. Studies have shown an association between obesity and chronic inflammation with enhanced neutrophil activity, increased superoxide radicals, and NET formation [97, 98]. Moorthy et al. show that the neutrophils of mice fed with high-fat diet are more prone to spontaneous NET formation, compared with neutrophils derived from mice fed with low-fat diet [99]. The same is seen in mice fed with high-fat diet and infected with inlfuenza compared with the mice fed with low-fat diet [100]. There is an increase in obesity globally, necessitating more studies into this condition and the link to the other metabolic conditions. This will inform on management of conditions caused or exacerbated by obesity and how NETs play a role in this.

\section{Potential Anti-NET Therapeutics}

Although NETs can be beneficial, the detrimental effect of NETs can cause excessive tissue damage and pathology. There are studies evaluating the possible effects of certain compounds against NETs as illustrated in Table 1, and more studies need to be considered to mitigate the negative effects of NETosis.

\section{Anti-Inflammatory/Immunomodulatory and NETs}

Acetylsalicylic acid (Aspirin) is a non-steroidal drug with an antithrombotic and an anti-inflammatory effect used in the management of inflammatory symptoms. It functions through the irreversible acetylation of cyclooxygenase enzyme (COX), and suppresses prostaglandin generation [101, 224]. It is used as an antiplatelet agent for prevention of arterial thromboses as it inhibits thromboxane A2 [225, 226]. Thromboxane A2 is a vasoconstrictor that activates new platelets increasing platelet aggregation, an important function during tissue injury, inflammation, and healing([227]). Platelets are the primary effector cells of hemostasis [227], but recent evidence indicates that they play a direct role in innate immunity by interacting with pathogens or recognize pathogen-associated molecular patterns (PAMPs) [228, 229]. They facilitate innate immunity and activate NETosis via platelet-neutrophil interaction [51, 230]. Platelet activation through TLR2 and TLR4 leads to the expression of Pselectin which binds to neutrophil receptor (PSGL-1) inducing NETosis as demonstrated in mice [24, 26, 102]. NETosis is also mediated by the binding of $\alpha \mathrm{M} \beta 2$ (MAC-1) on neutrophils to glycoprotein $1 \mathrm{~b} \alpha(\mathrm{GP} 1 \mathrm{~b} \alpha)$ on platelets generating NETs in liver and lungs during endotoxemia and in septic conditions [231, 232]. In addition to LPS, platelets can be activated by thrombin and arachidonic acid to form NETs $[103,230]$. Upon activation, platelets secrete soluble mediators including high-mobility group box-1 (HMBG-1) [25], platelet factor 4 (PF4), and CCL5 (RANTES) that induce NETosis via the neutrophil $G$ protein coupled receptors [104]. The interactions between platelets and neutrophils mediate NETosis, and inhibition of this interaction using antiplatelet therapy has the potential to inhibit NET formation $[105,106]$. In a study conducted on endotoxin-triggered acute lung injury, pretreatment of mice with aspirin showed a decreased intravascular NET formation and reduced degree of lung injury $[103,106]$. In another study on effects of NETs on transplantation in mice, they discovered that platelet activation was also inhibited by aspirin [107]. Lapponi et al. conducted another study where they treated neutrophils with a steroidal immunomodulatory drug (dexamethasone) or aspirin, and discovered that dexamethasone had no effect, while aspirin prevented NET formation [108]. They demonstrated that aspirin functions by inhibiting NF- $\mathrm{kB}$, an inflammatory transcriptional regulator, that promotes NETosis. These results show that aspirin could be a useful therapy in the management of pathologic NETosis induced by platelets, but we have to keep in mind the side effects of aspirin. Aspirin is a blood thinner and predisposes patients to stomach ulcers, so more studies are needed to find out which conditions could benefit from treatment with aspirin, without the excessive side effects.

Cyclosporine $A$ is an immunosuppressant drug widely used in post-allogeneic organ transplant to reduce the activity of the patient's immune system, and therefore the risk of organ rejection $[109,110]$. It causes reversible inhibition of immunocompetent lymphocytes and has been used to manage fungal infections, rheumatoid arthritis, asthma, dermatologic drug, and immunosuppressive agent $[110,111]$. The mechanism of action of cyclosporine A involves binding to cytophilin, resulting in the downregulation of NFAT (nuclear factor of activated $\mathrm{T}$ cells) transcription factor and inhibiting the calcineurin pathway subsequently inhibiting NET formation [111, 112]. Gupta et al. analyzed the role of cyclosporine A, ascomycin (a macrolide with strong immunosuppressant 


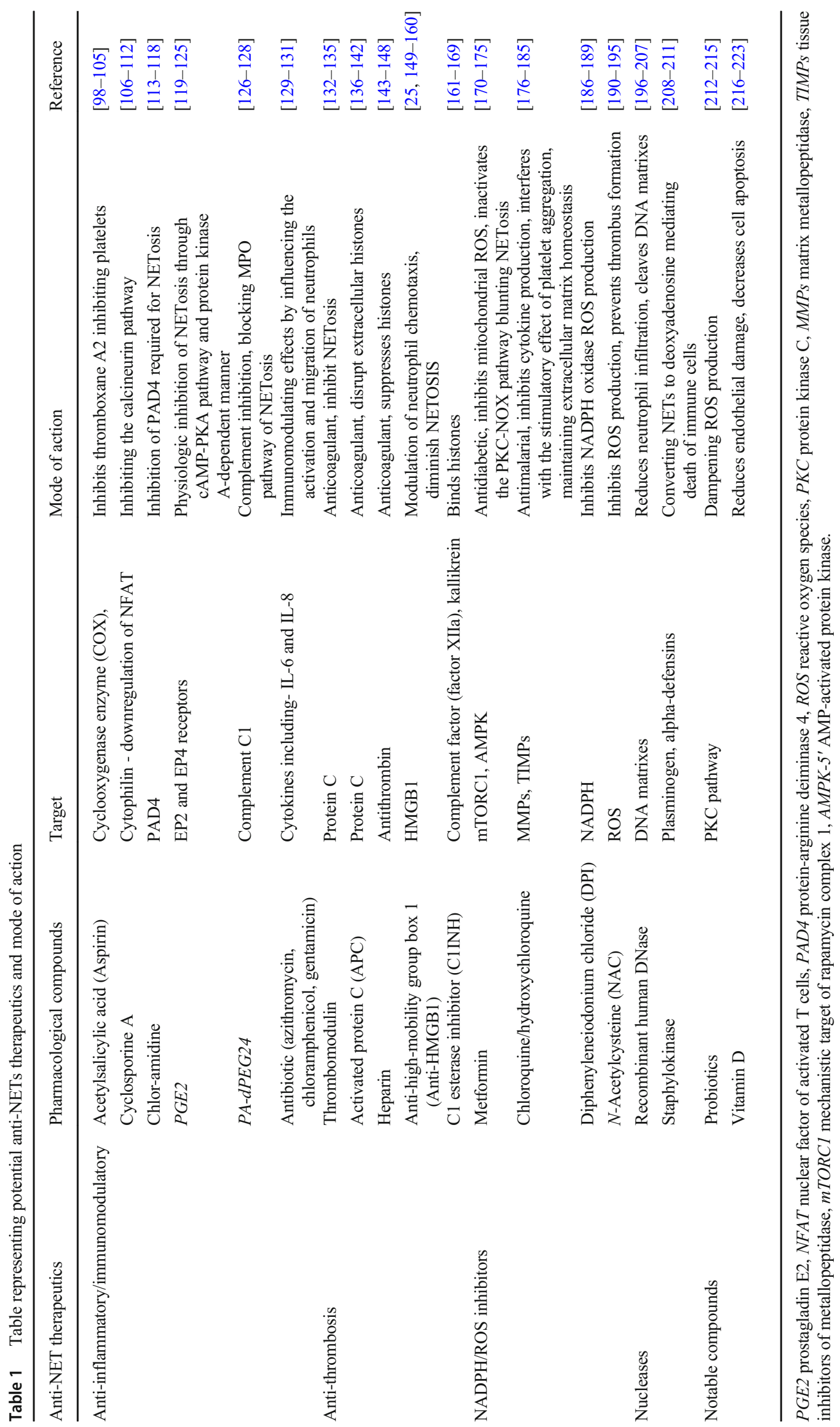


properties), and rapamycin (a cell anti-proliferative and immunosuppressive agent), on both extra and intracellular calcium pools and their modulation in NETosis. Their data indicated that a combination of ascomycin and cyclosporine A reduced NETosis, but the same effect was not evident following treatment with rapamycin [113]. This opens up the possibility to therapeutically suppress or modulate NETosis using cyclosporine A or a combination therapy with ascomycin. There were no other studies we could find in this area, and this could be due to the fact that cyclosporine $\mathrm{A}$ and immunosuppressive drugs may impair normal host immune responses to microbes $[114,115]$, predisposing patients to frequent infections. Therefore, there is a need for more studies into how these drugs could be formulated to manage NETosis safely.

Chlor-amidine (Cl-amidine) is a compound designed to irreversibly inhibit protein-arginine deiminase (PAD) through covalent modification at the active site of the enzymes [116]. As described above, PAD4 is an enzyme involved in NETosis; thus, inhibition of PAD4 is a possible therapeutic target. Avin et al. run a study to evaluate the effect of inhibition of PAD4 in NETosis using an antagomiR-155, a pleiotropic microRNA important in the regulation of immune responses, demonstrating a decreased induction of PAD4 mRNA and subsequent reduced NETs in response to PMA challenge [13]. In a mouse model of lupus, systemic treatment with the PAD4 inhibitor (BB-Cl-amidine) showed protection of the mice from developing NET-mediated vascular damage, endothelial dysfunction, and kidney injury. The study indicated that PAD4 inhibition markedly downregulates the expression of type I interferon-regulated genes and reduces proteinuria and immune complex deposition in the kidneys, while also protecting against skin disease [117]. Another study found that PAD4-deficient mice (both diabetic and nondiabetic) possess faster wound healing and re-epithelization processes than their wild-type counterparts. This effect was independent of wound infection suggesting that NETosis could hinder wound healing by limiting keratinocyte migration and re-epithelization [118]. It is therefore possible to target inhibition of PAD4 to inhibit NET formation; however, it is important to note that PAD4 may have other important functions in immunity which may be impaired $[119,120]$. In one study, they reported mixed results of pharmacological PAD4 inhibition using $\mathrm{Cl}$-amidine in human neutrophils, where NETosis induced by smoking was blocked by inhibiting of PAD4, but NETosis induced by cholesterol crystals was not blocked [121]. With these results, developing a suitable targeted therapy for PAD4 may be challenging thus the need for more carefully considered human studies on the function of PAD4 before using its inhibition as a strategy for management of NETosis.

$P G E 2$ - Prostaglandins (PGs) are members of the eicosanoid family synthesized from arachidonic acid via COX enzymes and produced by nearly all cells within the body. PGE2 is the most abundant prostaglandin in the human body and has been shown to influence both inflammatory and in some cases anti-inflammatory effects $[122,123]$. Shishikura et al. evaluated the effects of PGE2, agonists and antagonists of its receptors, and modulators of the cAMP-PKA pathway on the formation of NETs in vitro (in isolated neutrophils) and in vivo in a mouse model. They also discovered that PGE2 inhibited PMA-induced NET formation in vitro through EP2 and EP4. Exogenous PGE2 treatment limited NETosis of neutrophils collected from normal human volunteers and naive mice in an exchange protein activated by cAMP- and protein kinase A-dependent manner demonstrating a physiologic inhibition of NETosis. Incubation with a cell-permeable cAMP analogue, dibutyryl cAMP, or various inhibitors of a cAMPdegrading enzyme, rolipram (PDE4 inhibitor), and butaprost, (EP2 receptor agonist) also suppressed NET formation [124]. Interestingly, Domingo et al. conducted a study in murine bone marrow transplant mice (BMT) where neutrophils overexpress COX-2 and overproduce PGE2, leading to defective intracellular bacterial killing. They wanted to determine whether NETosis was defective after transplant and whether this was regulated by PGE2 signaling. Treatment of BMT neutrophils with rapamycin resulted in reduced NET formation relative to control cells while the EP2 receptor antagonist (PF-04418948) or the EP4 antagonist (AE3-208), G $\alpha_{\text {s- }}$ coupled receptors, restored NET formation suggesting that blocking PGE2-EP2 or EP4 signaling pathway restores NETosis [125]. These findings will contribute to the development of novel treatments for NETosis-related diseases although more studies need to be done to evaluate the effect of using PGE2 as a therapeutic. Although PGE2 is beneficial in management of SLE and other IFN- $\alpha$-dependent, Th1driven diseases [126], it could pose a challenge in conditions like arthritis $[233,234]$ associated with pain. PGE2 is known to contribute to pain as part of the inflammatory response, thus the need for more studies to evaluate its effects in different diseases compared with its benefits.

$P A-d P E G 24$ is a peptide inhibitor of complement $\mathrm{C} 1$ (PIC1) which mitigates peroxidase activity of MPO, hemoglobin, and myoglobin through a reversible process [235]. Defective complement action caused by dysregulation and acute and chronic tissue damage or transplants can lead to host cell attack contributing to inflammatory conditions [236, 237]. This is more so in the kidney which has been shown to be particularly sensitive to complement-mediated damage [127, 128]. It is known that complement effectors including C5a and membrane attack complex (sC5b-9) interact with and can stimulate human neutrophils to generate NETs. Subsequently, products of NETosis can activate complements causing a destructive loop [129]. Therapeutic complement inhibition is successfully used in paroxysmal nocturnal hemoglobinuria showing a promise in its use in other clinical conditions $[130,131]$. An article by Hair et al. demonstrated that 
PIC1 showed dose-dependent antioxidant activity, acting via the single electron transport (SET) and hydrogen atom transfer (HAT) mechanisms interfering with oxidation of cysteine residues. They showed that PA-dPEG24 achieved complete inhibition with complement effector levels equivalent to background. PA-dPEG24 was also able to dose-dependently inhibit NET formation by human neutrophils, stimulated by PMA, MPO, or immune complex activated human sera [235]. Their results suggest that PA-dPEG24 inhibition of NETs occurs by blocking the MPO pathway of NET formation. This provides proof that peptides can potentially be developed to inhibit complement-induced NETosis and be used to manage conditions worsened by NETs, although since complements are important in immune response, this needs to be researched further.

Antibiotics have been used in the management of bacterial infections and also have immunomodulating effects by influencing the properties of numerous immune cells, including neutrophils $[132,133]$. Bystrzycka et al. conducted a study to investigate the effects of azithromycin and chloramphenicol on degranulation, apoptosis, respiratory burst, and the release of NETs by neutrophils. Their study indicated that pretreatment of neutrophils with azithromycin and chloramphenicol decreases the release of NETs, with azithromycin showing a concentration-dependent effect on the respiratory burst in Bystrzycka et al.'s study [134]. Another article by MandaHandzlik et al. looked into the effects of cefotaxime and gentamicin on NETs and discovered that gentamicin inhibits NET release by human neutrophils, while cefotaxime had no impact on this process [133]. The information that antibiotics can modulate NET release can be useful in the management of infectious diseases or patients suffering from NET-related diseases. Since different antibiotics have different effects, there is need for more studies on their mode of action. This will inform on a possible compound for use in the management of NETs without interfering with their antimicrobial function.

\section{Anti-Thrombosis and NETs}

Thrombomodulin is a protein cofactor expressed on endothelial cell surfaces that modifies the substrate specificity of thrombin by an allosteric mechanism [238]. Thrombinthrombomodulin complex activates protein $\mathrm{C}$, initiating an essential anticoagulant pathway [238-240]. Thrombosis is the formation of a blood clot within a blood vessel caused by cytokines and other inflammatory mediators produced during an injury, obesity, and in some cases drugs, e.g., estrogen pills [241]. Large amounts of circulating cfDNA, present in NETs, can influence thrombus formation by impairing fibrinolysis creating a scaffold for the binding of red blood cells, platelets, fibrin, and coagulation factors [129]. Besides cfDNA, other NET components also exert procoagulant properties with extracellular histones inducing platelet activation, aggregation, and thrombin generation [81, 229, 242]. Immuno-thrombosis-induced coagulopathy may contribute to hypercoagulability which increases occurrence of multiple organ dysfunction and mortality [135-137]. Helms et al. did a study where they looked into the use of a recombinant human thrombomodulin (rhTM) and found out that it can limit procoagulant responses. rhTM was also shown to fully inhibit NETosis in neutrophils cultured with platelets and in the presence of LPS [138]. There is not much research in effect of rhTM, but this provides a starting point for further research into its potential use to inhibit NETs.

Activated protein $C$ (APC) is a multifunctional serine protease produced in blood by vitamin $\mathrm{K}$-activating protein $\mathrm{C}$. APC has anticoagulant, cytoprotective, and anti-inflammatory activities $[139,140]$. Protein $C$ has been shown to be an important prognostic indicator in patients with sepsis. During sepsis, there is a reduction in the conversion of protein $\mathrm{C}$ to its active form due to the downregulation of thrombomodulin by inflammatory cytokines [141]. The antithrombotic effects of activated protein $\mathrm{C}$ is mediated by its ability to inhibit the formation of clotting factors Va and VIlla and disrupting extracellular histones [142, 243]. Healy et al. demonstrated that APC cleaves and detoxifies extracellular histones and prevents activated platelets from inducing NETosis. The pretreatment of neutrophils with APC before inducing NETosis inhibited platelet adhesion to NETs. They also used antibodies against the neutrophil receptors endothelial protein $\mathrm{C}$ receptor (EPCR), protease-activated receptor 3 (PAR3), and macrophage-1 antigen (Mac-1) which blocked APC inhibition of NETosis [244]. Another study demonstrated that the blockade of protein $\mathrm{C}$ activation lead to exacerbated sublethal LPS challenge to turn lethal, which was reversed by treatment with antibodies to histones [56, 245]. These findings suggest that the anti-inflammatory function of APC may include inhibition of NETosis. Drotrecogin alfa is a recombinant human activated protein $\mathrm{C}$ produced by Xigris approved for use in septic patients $[143,144,246]$. Studies should be done to evaluate if this and other similar compounds would be effective in minimizing NETosis in sepsis and other conditions with minimal side effects.

Heparin is a medication and naturally occurring glycosaminoglycan used as an anticoagulant (blood thinner). Specifically, it is used in the treatment of heart attacks and unstable angina, and also antagonizes the effects of histones [247, 248]. High levels of circulating histones have been positively correlated with disease severity in many disease conditions as they activate NF-KB pathway inducing the secretion of cytokines that amplify inflammation leading to organ damage [145-147]. Heparin has been shown to significantly suppress histone-induced disease [148, 149]. Studies have been done to evaluate the effect of unfractionated heparin, low molecular weight heparin, e.g., parnaparin and non-anticoagulant heparin $[148,150,151]$. These studies demonstrate that 
heparin was able to protect mice from organ damage and death by antagonizing circulating histones attenuating tissue damage. Administration of heparin, especially the nonanticoagulant heparin, is a novel and promising approach that may be further developed to treat patients with high levels of circulating histones potentially inhibiting NETosis without increasing the risk of bleeding.

Anti-high-mobility group box 1 (HMGB1) is an abundant protein that regulates chromosome architecture and also functions as a damage-associated molecular pattern molecule [249-251]. It plays a beneficial role in microbial eradication through its pro-inflammatory actions and modulation of neutrophil chemotaxis [252-256]. Platelets are the major source of HMGB1 within the thrombi and present it to neutrophils promoting NETosis [152-154, 257]. Vogel et al. determined that platelet-derived HMGB1 is a critical mediator of thrombosis from their study using generated transgenic mice with platelet-specific deletion of HMGB1 [25]. These effects were mediated via TLR4-and MyD88-dependent recruitment of platelet guanylyl cyclase (GC) toward the plasma membrane, followed by MyD88/GC complex formation and activation of the cGMP-dependent protein kinase I [25, 155]. Mice lacking HMGB1 in platelets exhibited increased bleeding times as well as reduced thrombus formation, platelet aggregation, inflammation, and organ damage during experimental trauma/ hemorrhagic shock $[25,156]$. Exposure of neutrophils to HMGB1 resulted in enhanced formation of NETs in vitro through TLR4-dependent processes contributing to inflammatory processes and tissue injury [157-160, 257]. Studies show that the use of anti-HMGB1 antibodies may diminish NET formation, as seen in a reduction of histone 3 and free DNA in the BAL fluid of LPS-treated mice that received neutralizing antibodies to HMGB1 [159, 161]. However, decreased levels of cytokines in the lungs after administration of antiHMGB1 antibodies to LPS-treated mice may not necessarily be a direct result of diminished NET formation but could reflect the effects of HMGB 1 on other pro-inflammatory pathways $[162,163]$. This is a promising area necessitating more research into how anti-HMGB1 interrupts NETosis, and possibly use it as a treatment option.

Cl esterase inhibitor $(\mathrm{C} 1 \mathrm{INH})$ is an acute phase protein found in blood and a serine protease inhibitor that targets the complement pathway, coagulation pathway (factor XIIa), and the contact system protease kallikrein. It is an endogenous inhibitor of $\mathrm{C} 1$ protein in the complement system [164, 258, 259]. C1-INH concentrates are approved for use in the management of hereditary angioedema (HAE), an autosomaldominant disease caused by C1-INH deficiency due to a mutation in the C1-inhibitor gene $[165,166]$. Studies have been done to evaluate whether CI-INH may protect from lung injury in vivo possibly explaining the underlying mechanisms mediating protection. These studies demonstrated that application of C1INH alleviates bleomycin-induced lung injury via direct interaction with extracellular histones [167, 168]. In vitro, C1INH was found to bind all histone types with the interaction being independent of its protease inhibitory activity, but dependent on its glycosylation status [169]. In vivo, histone-C1INH complexes were detected in bronchoalveolar lavage fluid from patients with acute respiratory distress syndrome and multiple models of lung injury [170]. The reactivecenter-cleaved C1INH attenuated pulmonary damage evoked by intravenous histones indicating that $\mathrm{C} 1 \mathrm{INH}$ administration may provide a new therapeutic option for disorders associated with histone release [171]. Wygrecka and his colleagues tested C1INH for its ability to bind and neutralize histones and determined that $\mathrm{C} 1 \mathrm{INH}$ can bind purified histones in vitro reducing epithelial cell death by blocking histone interactions with cell surface proteins [167]. In another study, there was evidence for active binding of the exogenous C1INH to extracellular and citrullinated histones released during NETosis suggesting an endogenous mechanism by which histones are potentially neutralized [172]. This mechanism could be exploited for therapeutic management of excessive NETosis in other conditions, but studies need to be done to evaluate the effectiveness of these and other compounds with similar effects.

\section{NADPH/ROS Inhibitors and NETs}

Metformin, a widely prescribed blood glucose-normalizing antidiabetic drug, suppresses immune responses. It mainly achieves this through the induction of AMP-activated protein kinase. AMPK is an enzyme that plays a role in cellular energy homeostasis, by activating glucose and fatty acid uptake and oxidation when cellular energy is low. Induction of AMPK subsequently inhibits the mammalian target of rapamycin (mTORC1), a pathway that regulates mammalian metabolism and physiology, by inhibiting mitochondrial ROS production [173]. This results in its direct effect on the cellular functions of various pro-inflammatory immune cells. Due to the ROS inhibitory effect of metformin, studies are underway to evaluate it as a drug for regulating autoimmune diseases, treating chronic autoimmune diseases and gero-protection $[174,175]$. Menegazzo et al. investigated the effect of metformin against NETosis and discovered that compared with a placebo, it significantly reduced the concentrations of NETs in vitro. They showed a reduction in elastase, proteinase-3, histones, and cfDNA, whereas glucose control with insulin exerted no significant effect [176]. Metformin was shown to prevent membrane translocation of PKC- $\beta$ II and activation of NOX in neutrophils altering pathologic changes in nuclear dynamics and DNA release $[177,178]$. This resulted in a blunted NETosis in response to PMA and calcium influx. This provides information for a possible use of metformin on the PKC-NOX pathway as an anti-NETosis therapy. 
Chloroquine/hydroxychloroquine is an antimalarial drug used to treat malaria and has effects on amoeba (a protozoa) and some viruses $[179,180]$. Studies are currently underway to evaluate its effects on the novel corona-2 virus (COVID19) that is currently causing a pandemic [181, 182]. Hydroxychloroquine (HDQ) is a slightly less potent derivative of chloroquine that is used in the treatment of malaria and as an immunosuppressive drug for management autoimmune conditions including SLE and RA [183, 260]. It exerts its immunosuppressive effect through inhibition of cytokine production with modulation of co-stimulatory molecules and also inhibits leukocyte phagocytosis [261, 262]. HDQ interferes with the stimulatory effect of platelet aggregation even in the presence of a thrombin agonist [263]. MMPs are matrix metalloproteinases which are enzymes involved in extracellular matrix remodeling, and TIMPs are counter regulatory tissue inhibitors of MMPs [184, 264] that have been extensively studied in SLE $[185,265]$. Research has shown that HDQ modulated MMPs-TIMPs interaction assisting in maintaining homeostasis of the extracellular matrix [266, 267] and may thus play a role in reducing NETs. In another study that looked at tumor-derived extracellular vesicle (EV), transportable vesicles important in the exchange of biological molecules between cells and induce formation of NETs [268, 269], HDQ was shown to inhibit neutrophil uptake of tumor-derived EVs, thus reducing NETosis [47, 186-188]. However, the precise mechanism of inhibiting the uptake is largely unknown.

Due to the associated complications of NETs in autoimmune conditions and cancer metastasis, it is important for future research efforts to focus on further investigation of these drugs and other new specific targets for prevention or control of the detrimental effects of NETs formation.

Diphenyleneiodonium chloride (DPI) is as a hypoglycemic agent able to block gluconeogenesis and respiration by inhibiting many enzymes; NADPH oxidase, nitric oxide synthase, xanthine oxidase, NADPH cytochrome P450 oxidoreductase and cholinesterase [189, 190]. DPI works by binding the heme group of NADPH oxidase, inhibiting of NADPH oxidase and thus inhibits ROS production [191]. Ostafin et al. evaluated the effect of DPI on ROS production in the context of NETs and discovered that addition of DPI to the sample led to a reduction of extracellular DNA release with the strongest inhibition noticed after adding $10 \mu \mathrm{M}$ DPI. These findings confirmed that DPI is able to block NET creation. However, the addition of DPI together with PMA or the addition of inhibitor initially and then washing it out before stimulation resulted in different levels of NET formation [192]. These findings necessitate more studies to look into the mechanism of action of DPI under different conditions and in different diseases as a potential therapeutic for NETs.

$N$-acetylcysteine (NAC), also known as Acetylcysteine, is a medication used to treat acetaminophen overdose [193] and to loosen thick mucus in individuals with cystic fibrosis or chronic obstructive pulmonary disease [194]. It also functions as an antioxidant which helps mitigate symptoms for a variety of diseases exacerbated by ROS species [195, 196]. Zawrotniak and his team evaluated the effect of NAC, ketoprofen, and ethamsylate on NETosis and observed a reduction of ROS production in a dose-dependent manner. NAC inhibited netosis, but in the presence of hydrogen peroxide, this neutrophil ability was restored indicating that NAC influences NET formation by modulating ROS productivity [197]. The administration of ethamsylate led to a significant reduction in NET formation, but this effect was not restored by hydrogen peroxide suggesting an additional side effect of this drug. Ketoprofen seemed to promote ROS-independent NET release, simultaneously inhibiting ROS production [197]. Brianna et al. used an acute pulmonary thrombosis model in vivo where NAC reduced thrombus formation to a similar extent as the irreversible platelet inhibitor aspirin [198]. In vitro analysis of platelet activation revealed that NAC reduced thrombin-induced platelet-leukocyte aggregate formation in mice model of mutated Janus kinase 2, a common mutation found in patients with chronic hematologic malignancies (CHM), and reduced NET formation in primary human neutrophils from patients with $\mathrm{CHM}$ as well as healthy controls [198]. These results strongly suggest that the therapeutic strategies applied in many neutrophil-mediated diseases should take into account the NET-associated effects and that studies should look at the effect of these compounds in other diseases.

\section{Nucleases and NETs}

Recombinant human DNase, marketed as Pulmozyme (Dornase alfa) by Genentech, is a highly purified solution of recombinant human deoxyribonuclease I (rhDNase). This is an enzyme which selectively cleaves DNA and has been used to hydrolyze the DNA present in sputum/mucus of cystic fibrosis patients and reduces viscosity in the lungs promoting clearance of secretions [199]. Nucleases perform various functions like acquiring nucleotide nutrients, allowing or preventing uptake of foreign DNA, controlling biofilm formation/dispersal/architecture, aiding some pathogens in invading host by tissue damage, degrading DNA matrixes, and immunomodulating the host immune response [200-202]. Studies have demonstrated the destructive effect of DNase on DNA-nucleoprotein, and immune complexes, providing a rational way to interfere with the disease processes in SLE and lupus nephritis [203]. Numerous other studies have evaluated the effect of rhDNase on NETs, with results showing a reduction of NETosis with reduced neutrophil infiltration reducing the inflammatory response [204-206]. Albadawi et al. conducted a study where they observed reduced detection of extracellular traps in post-ischemic muscle but did not alter skeletal muscle fiber injury, levels of pro-inflammatory 
molecules, or ATP level. RhDNase treatment enhanced postischemic hindlimb perfusion, decreased infiltrating inflammatory cells, and reduced the expression of thrombinantithrombin III [207]. In addition, DNase I decreases tumor volume in rats when injected intramuscularly or intraperitoneally in conjunction with other proteases (papain, trypsin, and chymotrypsin) [208]; however, it is not known whether these effects are due primarily to NET inhibition, thus the need for more studies. Findings from a different study, showed that early and concurrent treatment with DNase I and antibiotics resulted in improved survival, reduced bacteremia, and organ dysfunction in septic conditions [209]) suggesting a possible combination therapy to control NETosis. Additionally, DNase I injection may have off-target effects that need to be considered in its use for control of NETs or they may fail to function as expected in vitro [210].

Staphylokinase is an exoprotein produced by Staphylococcus aureus, which activates host plasminogen [211]. It induces extracellular release of alpha-defensins from polymorphonuclear cells promoting a complex formation between alpha-defensins and staphylokinase. The effect of this interaction is an almost complete inhibition of the bactericidal effect of alpha-defensins [211]. Thammavongsa et al. reported that $S$. aureus escapes these defenses by converting NETs to deoxyadenosine, which triggers the caspase-3-mediated death of immune cells [212].Thus, the pathogenesis of $S$. aureus infections has evolved to anticipate host defenses and to repurpose them for the destruction of the immune system [213, 214]. Secretory nucleases also provide means of survival to other bacteria like iron-reducing Shewanella and such functions help them adapt and survive proficiently [200]. Other than their pro-pathogen roles in survival, nucleases can be used directly as therapeutics due to their biological functions and medical applications in diagnosis, immunoprophylaxis, and autoimmune therapy. In the future, these enzymes can impact human medicine positively by opening new avenues for therapeutics which have otherwise reached saturation due to multi-drug resistance.

\section{Notable Compounds}

Probiotics are live microorganisms promoted with claims that they provide health benefits when consumed, generally by improving or restoring the gut flora $[215,216]$. Probiotics are considered generally safe for consumption but may cause unwanted side effects and bacteria-host interactions in rare cases. Alterations in the gut microbiota, as well as the presence of local and systemic markers of inflammation, are strongly associated with the manifestation of a spectrum of intestinal disorders [217]. Linda et al. investigated the effects of a nonpathogenic, enteropathogenic, and probiotic bacteria on the dynamics of NET formation using murine bone marrow-derived neutrophils and the neutrophil- differentiated human myeloid cell line DHL-60. They demonstrate that the probiotic Lactobacillus rhamnosus strain GG (LGG) inhibits both PMA and S. aureus induced NETs by inhibiting PKC pathway and dampening ROS production disrupting NETosis supporting its antioxidative capacity [218]. Given the presence of NETs in inflamed intestine [91], it is possible that some of the beneficial effects of LGG are attributable to its action on local neutrophils. Probiotics have been shown to protect against bacterial-induced cytotoxicity, but more studies need to be done to highlights the dynamic interaction between beneficial bacteria and neutrophils to inform on the usefulness of probiotics as gut-protective and immunomodulatory compounds.

Vitamin $D$ is a group of fat-soluble secosteroids important for increasing intestinal absorption minerals including calcium, magnesium, and phosphate. Vitamin D has other multiple biological effects including activating the innate immune system while dampening the adaptive immune systems [219-222]. In humans, vitamin D3 (cholecalciferol) and vitamin D2 (ergocalciferol) are the most important [223]. There are suggestions indicating the benefits of vitamins $\mathrm{D}$ on various conditions, but evidence is lacking on whether supplementation of vitamin D helps to reduce the risk of these diseases including asthma, tuberculosis, irritable bowel disease, depression, and other conditions [270, 271]. In the case of NETosis, Handono et al. evaluated the effect of hypovitamin D on NETs in SLE patients [272]. They demonstrated a significant decrease in early apoptosis with a moderate positive correlation between NE externalizations with early apoptosis. They concluded that vitamin D could reduce endothelial damage by decreasing NETosis activity [272]. This result may reveal the possibility of vitamin $D$ as supplementary therapy for SLE patients and other patients with hypo-vitamin D to prevent NETosis and endothelial damage.

\section{Tools and Models to Investigate the Impact of Proposed Treatments on NETosis}

Investigation of the impact of one or more of the therapeutics discussed above in modification of NET formation will vary depending upon the disease and drug of interest. Where there are animal models of a target disease (e.g., rheumatoid arthritis or psoriasis) administration of the therapeutic drug can be done in a placebo-controlled study evaluating different doses. Tools available include histological identification of NETs and comparison of NETs formed in placebo versus drugtreated animals manually or using available computer programs. One example from our own work involves using a bovine model of respiratory syncytial virus and examination of the role of ibuprofen, a cox-inhibitor which decreases proinflammatory prostaglandin production and thromboxane 2 [273]. Our theory is that ibuprofen would reduce NETosis 
by decreasing neutrophil-activating cytokines and platelet activation. In our study, lungs are harvested at necropsy, fixed and stained with antibodies against citrullinated histones and neutrophil elastase, to delineate the presence of neutrophil NETs. Another model is the use of neutrophils incubated in vitro with the drug to be tested and staining to determine if there is an effect on NETosis under different drug doses.

\section{Conclusion}

NETs have been implicated in many disease processes, and although they have a positive effect by clearing pathogens, they are also destructive due to the release of enzymes and other proteins that cause tissue injury. Control of NETs is quickly becoming a target for therapeutics in the management of various disease, but it is clear to see that the different compounds that inhibit or clear NETs may have other unwanted effects on the immune system. This makes it challenging to conclude that one compound works better that the other and thus the need for more research. There is a possibility that the management of NETs may require using a combination therapy that incorporate conventional treatments such fluid therapy, antibiotics, antivirals, and NET-targeted drugs. To potentially optimize treatment efficacy and outcome in clinical patients, it is important we run more studies to evaluate the mode of action of these compounds to pick the actual effective component of these drugs, while evaluating the effect in the overall immune system to ensure there are no other detrimental effects.

Contribution of Authors Victoria Mutua researched and wrote the review. Laurel Gershwin provided edits to the first draft and advice on the review composition.

Funding Information This publication was supported by funds from USDA NIFA, grant no. 2016-11003, awarded to Laurel Gershwin and UC Davis Comparative Medical Science Training Program (NIH grant no.: T32 OD011147).

\section{References}

1. Takei H, Araki A, Watanabe $\mathrm{H}$ et al (1996) Rapid killing of human neutrophils by the potent activator phorbol 12-myristate 13-acetate (PMA) accompanied by changes different from typical apoptosis or necrosis. J Leukoc Biol 59:229-240. https://doi.org/10. 1002/jlb.59.2.229

2. Brinkmann V, Zychlinsky A (2012) Neutrophil extracellular traps: is immunity the second function of chromatin? J Cell Biol 198: 773-783

3. Brinkmann V, Zychlinsky A (2007) Beneficial suicide: why neutrophils die to make NETs. Nat Rev Microbiol 5:577-582. https:// doi.org/10.1038/nrmicro 1710

4. Urban C, Zychlinsky A (2007) Netting bacteria in sepsis. Nat Med 13:403-404
5. Scapini P, Cassatella MA (2014) Social networking of human neutrophils within the immune system. Blood 124:710-719

6. Amulic B, Cazalet C, Hayes GL et al (2012) Neutrophil function: from mechanisms to disease. Annu Rev Immunol 30:459-489. https://doi.org/10.1146/annurev-immunol-020711-074942

7. Mantovani A, Cassatella MA, Costantini C, Jaillon S (2011) Neutrophils in the activation and regulation of innate and adaptive immunity. Nat Rev Immunol 11:519-531

8. Brinkmann V, Reichard U, Goosmann C et al (2004) Neutrophil extracellular traps kill bacteria. Science 303(80):1532-1535. https://doi.org/10.1126/science.1092385

9. Papayannopoulos V, Metzler KD, Hakkim A, Zychlinsky A (2010) Neutrophil elastase and myeloperoxidase regulate the formation of neutrophil extracellular traps. J Cell Biol 191:677-691. https://doi.org/10.1083/jcb.201006052

10. Reeves EP, Lu H, Jacobs HL et al (2002) Killing activity of neutrophils is mediated through activation of proteases by $\mathrm{K}+$ flux. Nature 416:291-297. https://doi.org/10.1038/416291a

11. Smith CK, Vivekanandan-Giri A, Tang C et al (2014) Neutrophil extracellular trap-derived enzymes oxidize high-density lipoprotein: an additional proatherogenic mechanism in systemic lupus erythematosus. Arthritis Rheum 66:2532-2544. https://doi.org/ 10.1002/art.38703

12. Parker H, Winterbourn CC (2013) Reactive oxidants and myeloperoxidase and their involvement in neutrophil extracellular traps. Front Immunol 3:424. https://doi.org/10.3389/fimmu.2012. 00424

13. Hawez A, Al-Haidari A, Madhi R et al (2019) MiR-155 regulates PAD4-dependent formation of neutrophil extracellular traps. Front Immunol 10. https://doi.org/10.3389/fimmu.2019.02462

14. Lewis HD, Liddle J, Coote JE et al (2015) Inhibition of PAD4 activity is sufficient to disrupt mouse and human NET formation. Nat Chem Biol 11:189-191. https://doi.org/10.1038/nchembio. 1735

15. Wang Y, Li M, Stadler S et al (2009) Histone hypercitrullination mediates chromatin decondensation and neutrophil extracellular trap formation. J Cell Biol 184:205-213. https://doi.org/10.1083/ jcb. 200806072

16. Martinod K, Demers M, Fuchs TA et al (2013) Neutrophil histone modification by peptidylarginine deiminase 4 is critical for deep vein thrombosis in mice. Proc Natl Acad Sci U S A 110:86748679. https://doi.org/10.1073/pnas. 1301059110

17. Branzk N, Lubojemska A, Hardison SE et al (2014) Neutrophils sense microbe size and selectively release neutrophil extracellular traps in response to large pathogens. Nat Immunol 15:1017-1025. https://doi.org/10.1038/ni.2987

18. Segal AW (2005) How neutrophils kill microbes. Annu Rev Immunol 23:197-223. https://doi.org/10.1146/annurev.immunol. 23.021704.115653

19. Petretto A, Bruschi M, Pratesi F et al (2019) Neutrophil extracellular traps (NET) induced by different stimuli: a comparative proteomic analysis. PLoS One 14:e0218946. https://doi.org/10.1371/ journal.pone.0218946

20. Bruschi M, Bonanni A, Petretto A et al (2020) Neutrophil extracellular traps profiles in patients with incident systemic lupus erythematosus and lupus nephritis. J Rheumatol 47:377-386. https://doi.org/10.3899/jrheum.181232

21. Park J, Wysocki RW, Amoozgar Z et al (2016) Cancer cells induce metastasis-supporting neutrophil extracellular DNA traps. Sci Transl Med 8. https://doi.org/10.1126/scitranslmed.aag1711

22. Liu D, Yang P, Gao M et al (2019) NLRP3 activation induced by neutrophil extracellular traps sustains inflammatory response in the diabetic wound. Clin Sci 133:565-582. https://doi.org/10. $1042 /$ CS20180600

23. Hirota T, Levy JH, Iba T (2020) The influence of hyperglycemia on neutrophil extracellular trap formation and endothelial 
glycocalyx damage in a mouse model of type 2 diabetes. Microcirculation. https://doi.org/10.1111/micc.12617

24. Clark SR, Ma AC, Tavener SA et al (2007) Platelet TLR4 activates neutrophil extracellular traps to ensnare bacteria in septic blood. Nat Med 13:463-469. https://doi.org/10.1038/nm1565

25. Vogel S, Bodenstein R, Chen Q et al (2015) Platelet-derived HMGB1 is a critical mediator of thrombosis. J Clin Invest 125: 4638-4654. https://doi.org/10.1172/JCI81660

26. Etulain J, Martinod K, Wong SL et al (2015) P-selectin promotes neutrophil extracellular trap formation in mice. Blood 126:242246. https://doi.org/10.1182/blood-2015-01-624023

27. Schauer C, Janko C, Munoz LE et al (2014) Aggregated neutrophil extracellular traps limit inflammation by degrading cytokines and chemokines. Nat Med 20:511-517. https://doi.org/10.1038/ nm.3547

28. Neumann A, Berends ETM, Nerlich A et al (2014) The antimicrobial peptide LL-37 facilitates the formation of neutrophil extracellular traps. Biochem J 464:3-11. https://doi.org/10.1042/ BJ20140778

29. Burgener SS, Schroder K (2019) Neutrophil extracellular traps in host defense. https://doi.org/10.1101/cshperspect.a037028

30. Delgado-Rizo V, Martínez-Guzmán MA, Iñiguez-Gutierrez L et al (2017) Neutrophil extracellular traps and its implications in inflammation: an overview. Front Immunol 8:81

31. Borchers AT, Chang C, Gershwin ME, Gershwin LJ (2013) Respiratory syncytial virus - a comprehensive review. Clin Rev Allergy Immunol 45:331-379

32. Saitoh T, Komano J, Saitoh Y et al (2012) Neutrophil extracellular traps mediate a host defense response to human immunodeficiency virus-1. Cell Host Microbe 12:109-116. https://doi.org/10. 1016/j.chom.2012.05.015

33. Narasaraju T, Yang E, Samy RP et al (2011) Excessive neutrophils and neutrophil extracellular traps contribute to acute lung injury of influenza pneumonitis. Am J Pathol 179:199-210. https://doi.org/10.1016/j.ajpath.2011.03.013

34. Muraro SP, De Souza GF, Gallo SW et al (2018) Respiratory syncytial virus induces the classical ROS-dependent NETosis through PAD-4 and necroptosis pathways activation. Sci Rep 8: 1-12. https://doi.org/10.1038/s41598-018-32576-y

35. Gwyer Findlay E, Currie SM, Davidson DJ (2013) Cationic host defence peptides: potential as antiviral therapeutics. BioDrugs 27: 479-493

36. Hoeksema M, Tripathi S, White M et al (2015) Arginine-rich histones have strong antiviral activity for influenza a viruses. Innate Immun 21:736-745. https://doi.org/10.1177/ 1753425915593794

37. McCormick A, Heesemann L, Wagener J et al (2010) NETs formed by human neutrophils inhibit growth of the pathogenic mold Aspergillus fumigatus. Microbes Infect 12:928-936. https://doi.org/10.1016/j.micinf.2010.06.009

38. Amulic B, Knackstedt SL, Abu Abed U et al (2017) Cell-cycle proteins control production of neutrophil extracellular traps. Dev Cell 43:449-462.e5. https://doi.org/10.1016/j.devcel.2017.10.013

39. Bruns S, Kniemeyer O, Hasenberg M et al (2010) Production of extracellular traps against aspergillus fumigatus in vitro and in infected lung tissue is dependent on invading neutrophils and influenced by hydrophobin roda. PLoS Pathog 6:1-18. https://doi. org/10.1371/journal.ppat.1000873

40. Carroll GM, Burns GL, Petit JA et al (2020) Does postoperative inflammation or sepsis generate neutrophil extracellular traps that influence colorectal cancer progression? A systematic review. Surg Open Sci. https://doi.org/10.1016/j.sopen.2019.12.005

41. Baker VS, Imade GE, Molta NB et al (2008) Cytokine-associated neutrophil extracellular traps and antinuclear antibodies in Plasmodium falciparum infected children under six years of age. Malar J:7. https://doi.org/10.1186/1475-2875-7-41
42. Abdallah DSA, Lin C, Ball CJ et al (2012) Toxoplasma gondii triggers release of human and mouse neutrophil extracellular traps. Infect Immun 80:768-777. https://doi.org/10.1128/IAI.05730-11

43. Guimarães-Costa AB, Nascimento MTC, Froment GS et al (2009) Leishmania amazonensis promastigotes induce and are killed by neutrophil extracellular traps. Proc Natl Acad Sci U S A 106: 6748-6753. https://doi.org/10.1073/pnas.0900226106

44. Díaz-Godínez C, Carrero JC (2019) The state of art of neutrophil extracellular traps in protozoan and helminthic infections. Biosci Rep. https://doi.org/10.1042/BSR20180916

45. Cools-Lartigue J, Spicer J, Najmeh S, Ferri L (2014) Neutrophil extracellular traps in cancer progression. Cell Mol Life Sci 71: 4179-4194

46. Richardson JJR, Hendrickse C, Gao-Smith F, Thickett DR (2017) Neutrophil extracellular trap production in patients with colorectal cancer in vitro. https://doi.org/10.1155/2017/4915062

47. Snoderly HT, Boone BA, Bennewitz MF (2019) Neutrophil extracellular traps in breast cancer and beyond: current perspectives on NET stimuli, thrombosis and metastasis, and clinical utility for diagnosis and treatment. Breast Cancer Res 21:1-13

48. Alfaro C, Teijeira A, Oñate C et al (2016) Tumor-produced Interleukin-8 attracts human myeloid-derived suppressor cells and elicits extrusion of neutrophil extracellular traps (NETs). Clin Cancer Res 22:3924-3936. https://doi.org/10.1158/10780432.CCR-15-2463

49. Zhu L, Liu L, Zhang Y et al (2018) High level of neutrophil extracellular traps correlates with poor prognosis of severe influenza a infection. J Infect Dis 217:428-437. https://doi.org/10. 1093/infdis/jix475

50. Li RHL, Johnson LR, Kohen C, Tablin F (2018) A novel approach to identifying and quantifying neutrophil extracellular trap formation in septic dogs using immunofluorescence microscopy. BMC Vet Res 14:1-7. https://doi.org/10.1186/s12917-018-1523-Z

51. Thålin C, Hisada Y, Lundström S et al (2019) Neutrophil extracellular traps. Arterioscler Thromb Vasc Biol 39:1724-1738. https://doi.org/10.1161/ATVBAHA.119.312463

52. Li RHL, Tablin F (2018) A comparative review of neutrophil extracellular traps in sepsis. Front Vet Sci 5:291

53. Ekaney ML, Otto GP, Sossdorf M et al (2014) Impact of plasma histones in human sepsis and their contribution to cellular injury and inflammation. Crit Care 18:543. https://doi.org/10.1186/ s13054-014-0543-8

54. Akgul C, Moulding DA, Edwards SW (2001) Molecular control of neutrophil apoptosis. FEBS Lett 487:318-322

55. Keshari RS, Jyoti A, Dubey M et al (2012) Cytokines induced neutrophil extracellular traps formation: implication for the inflammatory disease condition. PLoS One:7. https://doi.org/10. 1371/journal.pone.0048111

56. Xu J, Zhang X, Pelayo R et al (2009) Extracellular histones are major mediators of death in sepsis. Nat Med 15:1318-1321. https://doi.org/10.1038/nm.2053

57. Abrams ST, Zhang N, Manson J et al (2013) Circulating histones are mediators of trauma-associated lung injury. Am J Respir Crit Care Med 187:160-169. https://doi.org/10.1164/rccm.2012061037OC

58. Gupta S, Kaplan MJ (2016) The role of neutrophils and NETosis in autoimmune and renal diseases. Nat Rev Nephrol 12:402-413

59. Glennon-Alty L, Hackett AP, Chapman EA, Wright HL (2018) Neutrophils and redox stress in the pathogenesis of autoimmune disease. Free Radic Biol Med 125:25-35. https://doi.org/10.1016/ j.freeradbiomed.2018.03.049

60. Hoffmann JHO, Enk AH (2016) Neutrophil extracellular traps in dermatology: caught in the NET. J Dermatol Sci 84:3-10

61. Engler D, Chezuba HP, Masuku P (2017) Psoriasis. SA Pharm J $84: 38-42$ 
62. Lowes MA, Bowcock AM, Krueger JG (2007) Pathogenesis and therapy of psoriasis. Nature 445:866-873

63. Boehncke WH, Schön MP (2015) Psoriasis. Lancet 386:983-994

64. Pinegin B, Vorobjeva N, Pinegin V (2015) Neutrophil extracellular traps and their role in the development of chronic inflammation and autoimmunity. Autoimmun Rev 14:633-640

65. Witko-Sarsat V, Pederzoli-Ribeil M, Hirsh E et al (2011) Regulating neutrophil apoptosis: new players enter the game. Trends Immunol 32:117-124

66. Dörner T, Giesecke C, Lipsky PE (2011) Mechanisms of B cell autoimmunity in SLE. Arthritis Res Ther 13. https://doi.org/10. 1186/ar3433

67. Lisnevskaia L, Murphy G, Isenberg D (2014) Systemic lupus erythematosus. In: The Lancet. Lancet Publishing Group, p 1878-1888. https://doi.org/10.1016/S0140-6736(14)60128-8

68. Pan L, Lu MP, Wang JH et al (2020) Immunological pathogenesis and treatment of systemic lupus erythematosus. World J Pediatr 16:19-30

69. Odqvist L, Jevnikar Z, Riise R et al (2019) Genetic variations in A20 DUB domain provide a genetic link to citrullination and neutrophil extracellular traps in systemic lupus erythematosus. Ann Rheum Dis 78:1363-1370. https://doi.org/10.1136/ annrheumdis-2019-215434

70. Chen W, Wang Q, Ke Y et al (2018) Review article neutrophil function in an inflammatory milieu of rheumatoid arthritis. https:// doi.org/10.1155/2018/8549329

71. Carmona-Rivera C, Carlucci PM, Moore E et al (2017) Synovial fibroblast-neutrophil interactions promote pathogenic adaptive immunity in rheumatoid arthritis. Sci Immunol 2. https://doi.org/ 10.1126/sciimmunol.aag 3358

72. Hidalgo AI, Carretta MD, Alarcón P et al (2019) Proinflammatory mediators and neutrophils are increased in synovial fluid from heifers with acute ruminal acidosis. BMC Vet Res 15: 1-10. https://doi.org/10.1186/s12917-019-1974-x

73. Khandpur R, Carmona-Rivera C, Vivekanandan-Giri A et al (2013) NETs are a source of citrullinated autoantigens and stimulate inflammatory responses in rheumatoid arthritis. Sci Trans1 Med 5:178ra40. https://doi.org/10.1126/scitranslmed.3005580

74. Apel F, Zychlinsky A, Kenny EF (2018) The role of neutrophil extracellular traps in rheumatic diseases. Nat Rev Rheumatol 14: 467-475

75. Wigerblad G, Kaplan MJ (2020) NETs spread ever wider in rheumatic diseases. Nat Rev Rheumatol 16:73-74

76. Herold KC, Vignali DAA, Cooke A, Bluestone JA (2013) Type 1 diabetes: translating mechanistic observations into effective clinical outcomes. Nat Rev Immunol 13:243-256

77. Berezin A (2019) Neutrophil extracellular traps: the core player in vascular complications of diabetes mellitus. Diabetes Metab Syndr Clin Res Rev 13:3017-3023

78. Jennette JC, Falk RJ (1997) Small-vessel vasculitis. N Engl J Med 3 37:1512-1523. https://doi.org/10.1056/ NEJM199711203372106

79. Hunder GG, Arend WP, Bloch DA et al (1990) The American College of Rheumatology 1990 criteria for the classification of vasculitis: introduction. Arthritis Rheum 33:1065-1067. https:// doi.org/10.1002/art.1780330802

80. Goeser MR, Laniosz V, Wetter DA (2014) A practical approach to the diagnosis, evaluation, and management of cutaneous smallvessel vasculitis. Am J Clin Dermatol 15:299-306. https://doi. org/10.1007/s40257-014-0076-6

81. Nakazawa D, Tomaru U, Yamamoto C et al (2012) Abundant neutrophil extracellular traps in thrombus of patient with microscopic polyangiitis. Front Immunol 3. https://doi.org/10.3389/ fimmu.2012.00333

82. Nakazawa D, Shida H, Tomaru U et al (2014) Enhanced formation and disordered regulation of NETs in myeloperoxidase-ANCA- associated microscopic polyangiitis. J Am Soc Nephrol 25:990997. https://doi.org/10.1681/ASN.2013060606

83. Mitroulis I, Kambas K, Chrysanthopoulou A et al (2011) Neutrophil extracellular trap formation is associated with IL-1 $\beta$ and autophagy-related signaling in gout. PLoS One. https://doi. org/10.1371/journal.pone.0029318

84. Lee KH, Kronbichler A, Park DDY et al (2017) Neutrophil extracellular traps (NETs) in autoimmune diseases: a comprehensive review. Autoimmun Rev 16:1160-1173. https://doi.org/10.1016/j. autrev.2017.09.012

85. Desai J, Steiger S, Anders HJ (2017) Molecular pathophysiology of gout. Trends Mol Med

86. Chambers TJ, Morson BC (1979) The granuloma in Crohn's disease. Gut 20:269-274. https://doi.org/10.1136/gut.20.4.269

87. Hedin CRH, Vavricka SR, Stagg AJ et al (2019) Gene and Mirna regulatory networks during different stages of Crohn's disease. J Crohn's Colitis 13:541-554. https://doi.org/10.1093/ECCO-JCC

88. Rogers BHG, Clark LM, Kirsner JB (1971) The epidemiologic and demographic characteristics of inflammatory bowel disease: an analysis of a computerized file of 1400 patients. J Chronic Dis 24:743-773. https://doi.org/10.1016/0021-9681(71)90087-7

89. Parkes G, Clare S, Goulding D et al (2006) Neutrophil activation and neutrophil extracellular trap formation in inflammatory bowel disease. Gastroenterology 130:A235

90. Gottlieb Y, Elhasid R, Berger-Achituv S et al (2018) Neutrophil extracellular traps in pediatric inflammatory bowel disease. Pathol Int. https://doi.org/10.1111/pin.12715

91. Dinallo V, Marafini I, Di Fusco D et al (2019) Neutrophil extracellulartraps sustain inflammatory signals in ulcerative colitis. J Crohn's Colitis. https://doi.org/10.1093/ecco-jcc/jjy215

92. Wärnberg J, Marcos A (2008) Low-grade inflammation and the metabolic syndrome in children and adolescents. Curr Opin Lipidol 19:11-15

93. Castro AM, Macedo-de la Concha LE, Pantoja-Meléndez CA (2017) Low-grade inflammation and its relation to obesity and chronic degenerative diseases. Rev Médica del Hosp Gen México 80:101-105. https://doi.org/10.1016/j.hgmx.2016.06.011

94. Wong SL, Demers M, Martinod K et al (2015) Diabetes primes neutrophils to undergo NETosis, which impairs wound healing. Nat Med. https://doi.org/10.1038/nm.3887

95. Frühbeck G (2004) The adipose tissue as a source of vasoactive factors. Curr Med Chem Cardiovasc Hematol Agents 2:197-208

96. Maurizi G, Della Guardia L, Maurizi A, Poloni A (2018) Adipocytes properties and crosstalk with immune system in obesity-related inflammation. J Cell Physiol 233:88-97. https:// doi.org/10.1002/jcp. 25855

97. Bonaventura A, Vecchié A, Abbate A, Montecucco F (2020) Neutrophil extracellular traps and cardiovascular diseases: an update. Cells 9:231. https://doi.org/10.3390/cells9010231

98. D’Abbondanza M, Martorelli EE, Ricci MA et al (2019) Increased plasmatic NETs by-products in patients in severe obesity. Sci Rep 9:1-10. https://doi.org/10.1038/s41598-019-51220-x

99. Narayana Moorthy A, Narasaraju T, Rai P et al (2013) In vivo and in vitro studies on the roles of neutrophil extracellular traps during secondary pneumococcal pneumonia after primary pulmonary influenza infection. Front Immunol 4:56. https://doi.org/10.3389/ fimmu.2013.00056

100. Moorthy AN, Tan KB, Wang S et al (2016) Effect of high-fat diet on the formation of pulmonary neutrophil extracellular traps during influenza pneumonia in BALB/c mice. Front Immunol 7:289. https://doi.org/10.3389/fimmu.2016.00289

101. Tarantino E, Amadio P, Squellerio I et al (2016) Role of thromboxane-dependent platelet activation in venous thrombosis: aspirin effects in mouse model. Pharmacol Res 107:415-425. https://doi.org/10.1016/j.phrs.2016.04.001 
102. Caudrillier A, Kessenbrock K, Gilliss BM et al (2012) Platelets induce neutrophil extracellular traps in transfusion-related acute lung injury. J Clin Invest 122:2661-2671. https://doi.org/10. 1172/JCI61303

103. Ortiz-Muñoz G, Mallavia B, Bins A et al (2014) Aspirin-triggered 15-epi-lipoxin a4 regulates neutrophil-platelet aggregation and attenuates acute lung injury in mice. Blood. https://doi.org/10.1182/ blood-2014-03-562876

104. Offermanns S (2006) Activation of platelet function through $\mathrm{G}$ protein-coupled receptors. Circ Res 99:1293-1304

105. Chen J, Shetty S, Zhang P et al (2014) Aspirin-triggered resolvin D1 down-regulates inflammatory responses and protects against endotoxin-induced acute kidney injury. Toxicol Appl Pharmacol. https://doi.org/10.1016/j.taap.2014.03.017

106. Tilgner J, Von Trotha KT, Gombert A et al (2016) Aspirin, but NotTirofiban displays protective effects in endotoxin induced lung injury. PLoS One. https://doi.org/10.1371/journal.pone.0161218

107. Sayah DM, Mallavia B, Liu F et al (2015) Neutrophil extracellular traps are pathogenic in primary graft dysfunction after lung transplantation. Am J Respir Crit Care Med 191:455-463. https://doi. org/10.1164/rccm.201406-1086OC

108. Lapponi MJ, Carestia A, Landoni VI et al (2013) Regulation of neutrophil extracellular trap formation by anti-inflammatory drugs. J Pharmacol Exp Ther 345:430-437. https://doi.org/10. 1124/jpet.112.202879

109. Matsuda S, Koyasu S (2000) Mechanisms of action of cyclosporine. Immunopharmacology 47:119-125. https://doi.org/10.1016/ S0162-3109(00)00192-2

110. Tedesco D, Haragsim L (2012) Cyclosporine: a review. J Transp Secur. https://doi.org/10.1155/2012/230386

111. Palmeiro BS (2013) Cyclosporine in veterinary dermatology. Vet Clin North Am Small Anim Pract (43), 153-171. https://doi.org/ 10.1016/j.cvsm.2012.09.007

112. Liberman AC, Druker J, Refojo D, Arzt E (2008) Molecular mechanisms of action of some immunosuppressive drugs. Medicina 68:455-464

113. Gupta AK, Giaglis S, Hasler P, Hahn S (2014) Efficient neutrophil extracellular trap induction requires mobilization of both intracellular and extracellular calcium pools and is modulated by cyclosporine A. PLoS One:9. https://doi.org/10.1371/journal.pone. 0097088

114. Fric J, Zelante T, Wong AYW et al (2012) NFAT control of innate immunity. Blood 120:1380-1389. https://doi.org/10.1182/blood2012-02-404475

115. Jha V, Chugh KS (2002) Posttransplant infections in the tropical countries. Artif Organs. https://doi.org/10.1046/j.1525-1594. 2002.07069.x

116. Witalison EE, Cui X, Causey CP et al (2015) Molecular targeting of protein arginine deiminases to suppress colitis and prevent colon cancer. Oncotarget. https://doi.org/10.18632/oncotarget.5937

117. Knight JS, Subramanian V, O'dell AA et alPeptidylarginine deiminase inhibition disrupts NET formation and protects against kidney, skin and vascular disease in lupus-prone MRL/lpr mice. https://doi.org/10.1136/annrheumdis-2014-205365

118. Fadini GP, Menegazzo L, Rigato M et al (2016) NETosis delays diabetic wound healing in mice and humans. Diabetes. https://doi. org/10.2337/db15-0863

119. Nakashima K, Arai S, Suzuki A et al (2013) PAD4 regulates proliferation of multipotent haematopoietic cells by controlling c-myc expression. Nat Commun. https://doi.org/10.1038/ ncomms 2862

120. Stadler SC, Vincent CT, Fedorov VD et al (2013) Dysregulation of PAD4-mediated citrullination of nuclear GSK3 $\beta$ activates TGF- $\beta$ signaling and induces epithelialto-mesenchymal transition in breast cancer cells. Proc Natl Acad Sci U S A. https://doi.org/ $10.1073 /$ pnas. 1308362110
121. Warnatsch A, Ioannou M, Wang Q, Papayannopoulos V (2015) Neutrophil extracellular traps license macrophages for cytokine production in atherosclerosis. Science (80). https://doi.org/10. 1126/science.aaa8064

122. Ricciotti E, Fitzgerald GA (2011) Prostaglandins and inflammation. Arterioscler Thromb Vasc Biol. https://doi.org/10.1161/ ATVBAHA.110.207449

123. Gad SE (2014) Prostaglandins. In: Encyclopedia of toxicology, third edn

124. Shishikura K, Horiuchi T, Sakata N et al (2016) Prostaglandin E2 inhibits neutrophil extracellular trap formation through production of cyclic AMP. Br J Pharmacol 173:319-331. https://doi.org/10. 1111/bph.13373

125. Domingo-Gonzalez R, Martínez-Colón GJ, Smith AJ et al (2016) Inhibition of neutrophil extracellular trap formation after stem cell transplant by prostaglandin E2. Am J Respir Crit Care Med 193: 186-197. https://doi.org/10.1164/rccm.201501-01610C

126. Fabricius D, Neubauer M, Mandel B et al (2010) Prostaglandin E 2 inhibits IFN- $\alpha$ secretion and Th1 costimulation by human plasmacytoid dendritic cells via E-prostanoid 2 and E-prostanoid 4 receptor engagement. J Immunol. https://doi.org/10.4049/ jimmunol.0902028

127. Zipfel PF, Heinen S, Józsi M, Skerka C (2006) Complement and diseases: defective alternative pathway control results in kidney and eye diseases. Mol Immunol 43: 97-106. https://doi.org/10. 1016/j.molimm.2005.06.015

128. Java A, Atkinson J, Salmon J (2013) Defective complement inhibitory function predisposes to renal disease. Annu Rev Med. https://doi.org/10.1146/annurev-med-072211-110606

129. de Bont CM, Boelens WC, Pruijn GJM (2019) NETosis, complement, and coagulation: a triangular relationship. Cell Mol Immunol 16: 19-27. https://doi.org/10.1038/s41423-018-0024-0

130. Hillmen P, Young NS, Schubert J et al (2006) The complement inhibitor eculizumab in paroxysmal nocturnal hemoglobinuria. $\mathrm{N}$ Engl J Med. https://doi.org/10.1056/NEJMoa061648

131. DeZern AE, Brodsky RA (2015) Paroxysmal nocturnal hemoglobinuria. A Complement-Mediated Hemolytic Anemia. Hematol Oncol Clin North Am 29:479-494.https://doi.org/10.1016/j.hoc. 2015.01.005

132. Tauber SC, Nau R (2008) Immunomodulatory properties of antibiotics. Curr Mol Pharmacol 1:68-79

133. Manda-Handzlik A, Bystrzycka W, Sieczkowska S et al (2017) Antibiotics modulate the ability of neutrophils to release neutrophil extracellular traps. Adv Exp Med Biol 944:47-52. https://doi. org/10.1007/55842016 59

134. Bystrzycka W, Manda-Handzlik A, Sieczkowska S et al (2017) Azithromycin and chloramphenicol diminish neutrophil extracellular traps (NETs) release. Int J Mol Sci 18:2666. https://doi.org/ 10.3390/ijms18122666

135. Gando S (2010) Microvascular thrombosis and multiple organ dysfunction syndrome. Crit Care Med

136. Licata G, Tuttolomondo A, Di Raimondo D et al (2009) Immunoinflammatory activation in acute cardio-embolic strokes in comparison with other subtypes of ischaemic stroke. Thromb Haemost. https://doi.org/10.1160/TH08-06-0375

137. Nguyen D, Coull BM (2017) Thrombosis. In: Primer on cerebrovascular diseases, second edn

138. Helms J, Clere-Jehl R, Bianchini E et al (2017) Thrombomodulin favors leukocyte microvesicle fibrinolytic activity, reduces NETosis and prevents septic shock-induced coagulopathy in rats. Ann Intensive Care 7:118. https://doi.org/10.1186/s13613-0170340-z

139. Dahlbäck B, Villoutreix BO (2005) The anticoagulant protein C pathway. FEBS Lett. https://doi.org/10.1016/j.febslet.2005.03. 001 
140. Howard BM, Cohen MJ (2016) Activated protein C. In: Trauma Induced Coagulopathy pp 91-114. https://doi.org/10.1007/978-3$319-28308-1$

141. Mosnier LO, Zlokovic BV, Griffin JH (2007) The cytoprotective protein C pathway. Blood 109:3161-3172. https://doi.org/10. 1182/blood-2006-09-003004

142. Griffin JH, Fernández JA, Gale AJ, Mosnier LO (2007) Activated protein C. J Thromb Haemost 5:73-80. https://doi.org/10.1111/j. 1538-7836.2007.02491.x.

143. Bernard GR, Vincent JL, Laterre PF et al (2001) Efficacy and safety of recombinant human activated protein $\mathrm{C}$ for severe sepsis. N Engl J Med. https://doi.org/10.1056/NEJM200103083441001

144. Vincent JL, Bernard GR, Beale R et al (2005) Drotrecogin alfa (activated) treatment in severe sepsis from the global open-label trial ENHANCE: further evidence for survival and safety and implications for early treatment. Crit Care Med. https://doi.org/ 10.1097/01.CCM.0000181729.46010.83

145. Skene PJ, Henikoff S (2013) Histone variants in pluripotency and disease. Development

146. Arrowsmith CH, Bountra C, Fish PV et al (2012) Epigenetic protein families: a new frontier for drug discovery. Nat Rev Drug Discov

147. Chen R, Kang R, Fan XG, Tang D (2014) Release and activity of histone in diseases. Cell Death Dis

148. Iba T, Hashiguchi N, Nagaoka I et al (2015) Heparins attenuated histone-mediated cytotoxicity in vitro and improved the survival in a rat model of histone-induced organ dysfunction. Intensive Care Med Exp 3:1-11. https://doi.org/10.1186/s40635-0150072-z

149. Wildhagen KCAAAA, De Frutos PG, Reutelingsperger CP et al (2014) Nonanticoagulant heparin prevents histone-mediated cytotoxicity in vitro and improves survival in sepsis. Blood 123:10981101. https://doi.org/10.1182/blood-2013-07-514984

150. Sanchez J (2017) Low molecular weight heparins - a new tool to disetangle from the NETs. Pharmacol Res 123:157

151. Manfredi AA, Rovere-Querini P, D'Angelo A, Maugeri N (2017) Low molecular weight heparins prevent the induction of autophagy of activated neutrophils and the formation of neutrophil extracellular traps. Pharmacol Res 123:146-156. https://doi.org/10. 1016/j.phrs.2016.08.008

152. Yang $\mathrm{X}$, Wang H, Zhang $\mathrm{M}$ et al (2015) HMGB1: a novel protein that induced platelets active and aggregation via Toll-like receptor-4, NF-kB and cGMP dependent mechanisms. Diagn Pathol 10:134. https://doi.org/10.1186/s13000-015-0348-3

153. Maugeri N, Franchini S, Campana L et al (2012) Circulating platelets as a source of the damage-associated molecular pattern HMGB1 in patients with systemic sclerosis. Autoimmunity. https://doi.org/10.3109/08916934.2012.719946

154. Stark K, Philippi V, Stockhausen S et al (2016) Disulfide HMGB1 derived from platelets coordinates venous thrombosis in mice. Blood. https://doi.org/10.1182/blood-2016-04-710632

155. Jong SP, Gamboni-Robertson F, He Q et al (2006) High mobility group box 1 protein interacts with multiple Toll-like receptors. Am J Phys Cell Physiol. https://doi.org/10.1152/ajpcell.00401.2005

156. Andrassy M, Volz HC, Igwe JC et al (2008) High-mobility group box-1 in ischemia-reperfusion injury of the heart. Circulation. https://doi.org/10.1161/CIRCULATIONAHA.108.769331

157. Huang H, Tohme S, Al-Khafaji AB et al (2015) Damageassociated molecular pattern-activated neutrophil extracellular trap exacerbates sterile inflammatory liver injury. Hepatology 62:600-614. https://doi.org/10.1002/hep.27841

158. Ma YH, Ma TT, Wang C et al (2016) High-mobility group box 1 potentiates antineutrophil cytoplasmic antibody-inducing neutrophil extracellular traps formation. Arthritis Res Ther. https://doi. org/10.1186/s13075-015-0903-Z
159. Tadie JM, Bae HB, Jiang S et al (2013) HMGB1 promotes neutrophil extracellular trap formation through interactions with Tolllike receptor 4. Am J Physiol Lung Cell Mol Physiol 304:L342. https://doi.org/10.1152/ajplung.00151.2012

160. Dyer MR, Chen Q, Haldeman S et al (2018) Deep vein thrombosis in mice is regulated by platelet HMGB1 through release of neutrophil-extracellular traps and DNA. Sci Rep. https://doi.org/ 10.1038/s41598-018-20479-x

161. Kang R, Zhang Q, Hou W et al (2014) Intracellular HMGB1 inhibits inflammatory nucleosome release and limits acute pancreatitis in mice. Gastroenterology 146:1097-1107.e8. https://doi. org/10.1053/j.gastro.2013.12.015

162. Okuma Y, Liu K, Wake H et al (2012) Anti-high mobility group box-1 antibody therapy for traumatic brain injury. Ann Neurol. https://doi.org/10.1002/ana.23602

163. Liu K, Mori S, Takahashi HK et al (2007) Anti-high mobility group box 1 monoclonal antibody ameliorates brain infarction induced by transient ischemia in rats. FASEB J. https://doi.org/ 10.1096/fj.07-8770com

164. Davis AE, Lu F, Mejia P (2010) C1 inhibitor, a multi-functional serine protease inhibitor. Thromb Haemost 104:886-93. https:// doi.org/10.1160/TH10-01-0073

165. Bouillet L, Boccon-Gibod I, Gompel A et al (2017) Hereditary angioedema with normal $\mathrm{C} 1$ inhibitor: clinical characteristics and treatment response with plasma-derived human $\mathrm{C} 1$ inhibitor concentrate (Berinert $\left.{ }^{\circledR}\right)$ in a french cohort. Eur J Dermatol https:// www.ncbi.nlm.nih.gov/pubmed?term $=28251901$. Accessed 13 May 2020

166. Zuraw BL, Bork K, Binkley KE et al (2012) Hereditary angioedema with normal $\mathrm{C} 1$ inhibitor function: consensus of an international expert panel. Allergy Asthma Proc 33 Suppl 1:S145-S156. https://doi.org/10.2500/aap.2012.33.3627

167. Wygrecka M, Kosanovic D, Wujak L et al (2017) Antihistone properties of $\mathrm{C} 1$ esterase inhibitor protect against lung injury. Am J Respir Crit Care Med 196:186-199. https://doi.org/10. 1164/rccm.201604-0712OC

168. Singer M, Jones AM (2010) Bench-to-bedside review: the role of $\mathrm{C} 1$-esterase inhibitor in sepsis and other critical illnesses. Crit Care 15:203

169. Liu D, Cai S, Gu X et al (2003) C1 inhibitor prevents endotoxin shock via a direct interaction with lipopolysaccharide. J Immunol. https://doi.org/10.4049/jimmunol.171.5.2594

170. Lu F, Fernandes SM, Davis AE (2013) The effect of C1 inhibitor on myocardial ischemia and reperfusion injury. Cardiovasc Pathol. https://doi.org/10.1016/j.carpath.2012.05.003

171. Caliezi C, Wuillemin WA, Zeerleder S et al (2000) C1-esterase inhibitor: an anti-inflammatory agent and its potential use in the treatment of diseases other than hereditary angioedema. Pharmacol Rev 52:91-112

172. Lefrançais E, Looney MR (2017) Neutralizing extracellular histones in acute respiratory distress syndrome. Am J Respir Crit Care Med 196:122-124

173. Rena G, Hardie DG, Pearson ER (2017) The mechanisms of action of metformin. Diabetologia 60:1577-1585. https://doi.org/10. 1007/s00125-017-4342-z

174. Campbell JM (2019) Metformin. In: Encyclopedia of biomedical gerontology

175. Martin-Montalvo A, Mercken EM, Mitchell SJ et al (2013) Metformin improves healthspan and lifespan in mice. Nat Commun. https://doi.org/10.1038/ncomms3192

176. Menegazzo L, Scattolini V, Cappellari R et al (2018) The antidiabetic drug metformin blunts NETosis in vitro and reduces circulating NETosis biomarkers in vivo. Acta Diabetol 55:593-601. https://doi.org/10.1007/s00592-018-1129-8

177. Gallo A, Ceolotto G, Pinton P et al (2005) Metformin prevents glucose-induced protein kinase $\mathrm{C}-\beta 2$ activation in human 
umbilical vein endothelial cells through an antioxidant mechanism. Diabetes. https://doi.org/10.2337/diabetes.54.4.1123

178. Batchuluun B, Inoguchi T, Sonoda N et al (2014) Metformin and liraglutide ameliorate high glucose-induced oxidative stress via inhibition of PKC-NAD(P)H oxidase pathway in human aortic endothelial cells. Atherosclerosis. https://doi.org/10.1016/j. atherosclerosis.2013.10.025

179. Keyaerts E, Vijgen L, Maes P et al (2004) In vitro inhibition of severe acute respiratory syndrome coronavirus by chloroquine. Biochem Biophys Res Commun. https://doi.org/10.1016/j.bbrc. 2004.08.085

180. Savarino A, Boelaert JR, Cassone A et al (2003) Effects of chloroquine on viral infections: an old drug against today's diseases? Lancet Infect Dis Lancet Infect Dis 3:722-727. https://doi.org/10. 1016/S1473-3099(03)00806-5

181. Touret F, de Lamballerie X (2020) Of chloroquine and COVID19. Antivir Res 177. https://doi.org/10.1016/j.antiviral.2020. 104762

182. Cortegiani A, Ingoglia G, Ippolito M et al (2020) A systematic review on the efficacy and safety of chloroquine for the treatment of COVID-19. J Crit Care. https://doi.org/10.1016/j.jcrc.2020.03. 005

183. Suarez-Almazor ME, Belseck E, Shea B et al (2000) Antimalarials for treating rheumatoid arthritis. Cochrane Database Syst Rev. https://doi.org/10.1002/14651858.cd000959

184. Amin M, Pushpakumar S, Muradashvili N et al (2016) Regulation and involvement of matrix metalloproteinases in vascular diseases. Front Biosci Landmark 21:89-118

185. Vira H, Pradhan V, Umare V et al (2019) Role of polymorphisms in MMP-9 and TIMP-1 as biomarkers for susceptibility to systemic lupus erythematosus patients. Biomark Med 13:33-43. https:// doi.org/10.2217/bmm-2018-0169

186. Murthy P, Singhi AD, Ross MA et al (2019) Enhanced neutrophil extracellular trap formation in acute pancreatitis contributes to disease severity and is reduced by chloroquine. Front Immunol: 10. https://doi.org/10.3389/fimmu.2019.00028

187. Boone BA, Murthy P, Miller-Ocuin J et al (2018) Chloroquine reduces hypercoagulability in pancreatic cancer through inhibition of neutrophil extracellular traps. BMC Cancer 18. https://doi.org/ 10.1186/s12885-018-4584-2

188. Boone BA, Orlichenko L, Schapiro NE et al (2015) The receptor for advanced glycation end products (RAGE) enhances autophagy and neutrophil extracellular traps in pancreatic cancer. Cancer Gene Ther 22:326-334. https://doi.org/10.1038/cgt.2015.21

189. Riganti C, Gazzano E, Polimeni M et al (2004) Diphenyleneiodonium inhibits the cell redox metabolism and induces oxidative stress. J Biol Chem. https://doi.org/10.1074/ jbc.M406314200

190. Massart C, Giusti N, Beauwens R et al (2014) Diphenyleneiodonium, an inhibitor of NOXes and DUOXes, is also an iodide-specific transporter. FEBS Open Bio. https://doi. org/10.1016/j.fob.2013.11.007

191. Hasan RN, Schafer AI (2008) Hemin upregulates Egr-1 expression in vascular smooth muscle cells via reactive oxygen species ERK-1/2-Elk-1 and NF-kB. Circ Res. https://doi.org/10.1161/ CIRCRESAHA.107.155143

192. Ostafin M, Pruchniak MP, Ciepiela O et al (2016) Different procedures of diphenyleneiodonium chloride addition affect neutrophil extracellular trap formation. Anal Biochem 509:60-66. https://doi.org/10.1016/j.ab.2016.05.003

193. Hodgman MJ, Garrard AR (2012) A review of acetaminophen poisoning. Crit Care Clin 28:499-516. https://doi.org/10.1016/j. ccc.2012.07.006

194. Dekhuijzen PN, van Beurden WJ (2006) The role for Nacetylcysteine in the management of COPD. Int J Chron
Obstruct Pulmon Dis 1:99-106. https://doi.org/10.2147/copd. 2006.1.2.99

195. Aruoma OI, Halliwell B, Hoey BM, Butler J (1989) The antioxidant action of $\mathrm{N}$-acetylcysteine: its reaction with hydrogen peroxide, hydroxyl radical, superoxide, and hypochlorous acid. Free Radic Biol Med. https://doi.org/10.1016/0891-5849(89)90066-X

196. Aldini G, Altomare A, Baron G et al (2018) N-Acetylcysteine as an antioxidant and disulphide breaking agent: the reasons why. Free Radic Res 52:751-762. https://doi.org/10.1080/10715762. 2018.1468564

197. Zawrotniak M, Kozik A, Rapala-Kozik M (2015) View of selected mucolytic, anti-inflammatory and cardiovascular drugs change the ability of neutrophils to form extracellular traps (NETs). https:// doi.org/10.18388/abp.2015 1055

198. Craver BM, Ramanathan G, Hoang S et al (2020) NAcetylcysteine inhibits thrombosis in a murine model of myeloproliferative neoplasm. Blood Adv. https://doi.org/10.1182/ bloodadvances.2019000967

199. Shak S, Capon DJ, Hellmiss R et al (1990) Recombinant human DNase I reduces the viscosity of cystic fibrosis sputum. Proc Natl Acad Sci U S A 87:9188-9192. https://doi.org/10.1073/pnas.87. 23.9188

200. Sharma P, Garg N, Sharma A et al (2019) Nucleases of bacterial pathogens as virulence factors, therapeutic targets and diagnostic markers. Int J Med Microbiol 309:151354

201. Nishino T, Morikawa K (2002) Structure and function of nucleases in DNA repair: shape, grip and blade of the DNA scissors. Oncogene 21:9022-9032

202. Ain QU, Chung JY, Kim YH (2015) Current and future delivery systems for engineered nucleases: ZFN, TALEN and RGEN. J Control Release 205:120-127. https://doi.org/10.1016/j.jconrel. 2014.12.036

203. Macanovic M, Sinicropi D, Shak S et al (1996) The treatment of systemic lupus erythematosus (SLE) in NZB/W F1 hybrid mice; studies with recombinant murine DNase and with dexamethasone. Clin Exp Immunol 106:243-252. https://doi.org/10.1046/j.13652249.1996.d01-839.x

204. Meng W, Paunel-Görgülü A, Flohé S et al (2012) Deoxyribonuclease is a potential counter regulator of aberrant neutrophil extracellular traps formation after major trauma. Mediat Inflamm. https://doi.org/10.1155/2012/149560

205. Gray RD, McCullagh BN, McCray PB (2015) NETs and CF lung disease: current status and future prospects. Antibiotics 4:62-75

206. Mohanty T, Fisher J, Bakochi A et al (2019) Neutrophil extracellular traps in the central nervous system hinder bacterial clearance during pneumococcal meningitis. Nat Commun 10. https://doi. org/10.1038/s41467-019-09040-0

207. Albadawi H, Oklu R, Raacke Malley RE et al (2016) Effect of DNase I treatment and neutrophil depletion on acute limb ischemia-reperfusion injury in mice. J Vasc Surg 64:484-493. https://doi.org/10.1016/j.jvs.2015.01.031

208. Trejo-Becerril C, Pérez-Cardenas E, Gutiérrez-Díaz B et al (2016) Antitumor effects of systemic DNAse i and proteases in an in vivo model. Integr Cancer Ther. https://doi.org/10.1177/ 1534735416631102

209. Kaplan JB, Lovetri K, Cardona ST et al (2012) Recombinant human DNase i decreases biofilm and increases antimicrobial susceptibility in staphylococci. J Antibiot (Tokyo). https://doi.org/10. 1038/ja.2011.113

210. Saffarzadeh M, Juenemann C, Queisser MA et al (2012) Neutrophil extracellular traps directly induce epithelial and endothelial cell death: a predominant role of histones. PLoS One 7. https://doi.org/10.1371/journal.pone.0032366

211. Jin T, Bokarewa M, Foster T et al (2004) Staphylococcus aureus resists human defensins by production of staphylokinase, a novel 
bacterial evasion mechanism. J Immunol 172:1169-1176. https:// doi.org/10.4049/jimmunol.172.2.1169

212. Thammavongsa V, Missiakas DM, Schneewind O (2013) Staphylococcus aureus degrades neutrophil extracellular traps to promote immune cell death. Science 342(80):863-866. https:// doi.org/10.1126/science.1242255

213. Ryu S, Song PI, Seo CH et al (2014) Colonization and infection of the skin by S. aureus: immune system evasion and the response to cationic antimicrobial peptides. Int J Mol Sci. https://doi.org/10. 3390/ijms 15058753

214. McCarthy AJ, Lindsay JA (2013) Staphylococcus aureus innate immune evasion is lineage-specific: a bioinfomatics study. Infect Genet Evol. https://doi.org/10.1016/j.meegid.2013.06.012

215. Bermudez-Brito M, Plaza-Díaz J, Muñoz-Quezada S et al (2012) Probiotic mechanisms of action. Ann Nutr Metab 61:160-174. https://doi.org/10.1159/000342079

216. Soccol CR, de Souza Vandenberghe LP, Spier MR et al (2010) The potential of probiotics: a review. Food Technol Biotechnol 48:413-434

217. Doron S, Snydman DR (2015) Risk and safety of probiotics. Clin Infect Dis. https://doi.org/10.1093/cid/civ085

218. Vong L, Lorentz RJ, Assa A et al (2014) Probiotic lactobacillus rhamnosus inhibits the formation of neutrophil extracellular traps. J Immunol. https://doi.org/10.4049/jimmunol.1302286

219. Liu PT, Stenger S, Li H et al (2006) Toll-like receptor triggering of a vitamin D-mediated human antimicrobial response. Science (80). https://doi.org/10.1126/science.1123933

220. Harvey NC, Cantorna MT (2013) Vitamin D and the immune system. In: Diet, immunity and inflammation pp 244-263. https://doi.org/10.1533/9780857095749.2.244

221. Bikle D (2009) Nonclassic actions of vitamin D. J Clin Endocrinol Metab 94:26-34. https://doi.org/10.1210/jc.2008-1454

222. Hewison $\mathrm{M}$ (2012) An update on vitamin D and human immunity. Clin Endocrinol 76:315-325. https://doi.org/10.1111/j.13652265.2011.04261.x

223. Fischer K (2019) Vitamin D. In: Principles of nutrigenetics and nutrigenomics: fundamentals of individualized nutrition pp 245 254. https://doi.org/10.1016/B978-0-12-804572-5.00032-X

224. Brighton TA, Eikelboom JW, Mann K et al (2012) Low-dose aspirin for preventing recurrent venous thromboembolism. N Engl J Med 367:1979-1987. https://doi.org/10.1056/ NEJMoa1210384

225. Wood AJJ, Patrono C (1994) Aspirin as an antiplatelet drug. N Engl J Med 330:1287-1294. https://doi.org/10.1056/ NEJM199405053301808

226. Catella-Lawson F, Reilly MP, Kapoor SC et al (2001) Cyclooxygenase inhibitors and the antiplatelet effects of aspirin. N Engl J Med 345:1809-1817. https://doi.org/10.1056/ NEJMoa003199

227. Léon C, Ravanat C, Freund M et al (2003) Differential involvement of the P2Y1 and P2Y12 receptors in platelet procoagulant activity. Arterioscler Thromb Vasc Biol 23:1941-1947. https:/ doi.org/10.1161/01.ATV.0000092127.16125.E6

228. Flaumenhaft R (2003) Molecular basis of platelet granule secretion. Arterioscler Thromb Vasc Biol 23:1152-1160

229. Weber C (2005) Platelets and chemokines in atherosclerosis: partners in crime. Circ Res 96:612-616

230. Carestia A, Kaufman T, Schattner M (2016) Platelets: new bricks in the building of neutrophil extracellular traps. Front Immunol 7: 271

231. Merza M, Rahman M, Zhang S et al (2014) Human thrombinderived host defense peptides inhibit neutrophil recruitment and tissue injury in severe acute pancreatitis. Am J Physiol Liver Physiol 307:G914-G921. https://doi.org/10.1152/ajpgi.00237. 2014
232. Jenne CN, Wong CHY, Zemp FJ et al (2013) Neutrophils recruited to sites of infection protect from virus challenge by releasing neutrophil extracellular traps. Cell Host Microbe 13:169-180. https://doi.org/10.1016/j.chom.2013.01.005

233. Schaible HG, Ebersberger A, Segond Von Banchet G (2002) Mechanisms of pain in arthritis. Ann N Y Acad Sci

234. Attur M, Krasnokutsky S, Statnikov A et al (2015) Low-grade inflammation in symptomatic knee osteoarthritis: prognostic value of inflammatory plasma lipids and peripheral blood leukocyte biomarkers. Arthritis Rheum. https://doi.org/10.1002/art.39279

235. Hair PS, Enos AI, Krishna NK, Cunnion KM (2018) Inhibition of immune complex complement activation and neutrophil extracellular trap formation by peptide inhibitor of complement C1. Front Immunol 9:558. https://doi.org/10.3389/fimmu.2018.00558

236. Botto M, Kirschfink M, Macor P et al (2009) Complement in human diseases: lessons from complement deficiencies. Mol Immunol

237. Klaska I, Nowak JZ (2007) The role of complement in physiology and pathology. Postepy Hig Med Dosw (Online) 61:167-77

238. Weiler H, Isermann BH (2003) Thrombomodulin. J Thromb Haemost 1:1515-1524. https://doi.org/10.1046/j.1538-7836. 2003.00306.x

239. Conway EM (2012) Thrombomodulin and its role in inflammation. Semin Immunopathol 34:107-125. https://doi.org/10.1007/ s00281-011-0282-8

240. Fuentes-Prior P, Iwanaga Y, Huber R et al (2000) Structural basis for the anticoagulant activity of the thrombin-thrombomodulin complex. Nature. https://doi.org/10.1038/35006683

241. Arnold DM, Kukaswadia S, Nazi I et al (2013) A systematic evaluation of laboratory testing for drug-induced immune thrombocytopenia. J Thromb Haemost. https://doi.org/10.1111/jth. 12052

242. Sørensen OE, Borregaard N (2016) Neutrophil extracellular traps the dark side of neutrophils. J Clin Invest 126:1612-1620

243. Griffin JH, Zlokovic BV, Mosnier LO (2015) Activated protein C: biased for translation. Blood 125:2898-2907. https://doi.org/10. 1182/blood-2015-02-355974

244. Healy LD, Puy C, Fernández JA et al (2017) Activated protein C inhibits neutrophil extracellular trap formation in vitro and activation in vivo. J Biol Chem 292:8616-8629. https://doi.org/10.1074/ jbc.M116.768309

245. Okajima K (2001) Regulation of inflammatory responses by natural anticoagulants. Immunol Rev 184:258-274. https://doi.org/ 10.1034/j.1600-065x.2001.1840123.x

246. Kalil AC, LaRosa SP (2012) Effectiveness and safety of drotrecogin alfa (activated) for severe sepsis: a meta-analysis and metaregression. Lancet Infect Dis. https://doi.org/10.1016/ S1473-3099(12)70157-3

247. Acquisto NM (2014) Heparin. In: Encyclopedia of toxicology, third edn

248. Wardrop D, Keeling D (2008) The story of the discovery of heparin and warfarin. Br J Haematol 141:757-763. https://doi.org/10. 1111/j.1365-2141.2008.07119.x

249. Tsung A, Tohme S, Billiar TR (2014) High-mobility group box-1 in sterile inflammation. J Intern Med 276:425-443. https://doi.org/ 10.1111/joim.12276

250. Tang D, Kang R, Zeh HJ, Lotze MT (2011) High-mobility group box 1, oxidative stress, and disease. Antioxid Redox Signal 14: 1315-1335. https://doi.org/10.1089/ars.2010.3356

251. Malarkey CS, Churchill MEA (2012) The high mobility group box: the ultimate utility player of a cell. Trends Biochem Sci 37: 553-562. https://doi.org/10.1016/j.tibs.2012.09.003

252. Lotze MT, Tracey KJ (2005) High-mobility group box 1 protein (HMGB1): nuclear weapon in the immune arsenal. Nat Rev Immunol 5:331-342. https://doi.org/10.1038/nri1594 
253. Park JS, Svetkauskaite D, He Q et al (2004) Involvement of tolllike receptors 2 and 4 in cellular activation by high mobility group box 1 protein. J Biol Chem. https://doi.org/10.1074/jbc. M306793200

254. Mayansky AN, Mayansky NA (2009) Late-acting cytokine HMGBI: mediatory functions and prospects for clinical application. Immunologiya 4:232-237

255. Lee SA, Kwak MS, Kim S, Shin JS (2014) The role of high mobility group box 1 in innate immunity. Yonsei Med J 55: 1165-1176. https://doi.org/10.3349/ymj.2014.55.5.1165

256. Matsuoka N, Itoh $\mathrm{T}$, Watarai $\mathrm{H}$ et al (2010) High-mobility group box 1 is involved in the initial events of early loss of transplanted islets in mice. J Clin Invest. https://doi.org/10.1172/JCI41360

257. Maugeri N, Campana L, Gavina M et al (2014) Activated platelets present high mobility group box 1 to neutrophils, inducing autophagy and promoting the extrusion of neutrophil extracellular traps. $\mathrm{J}$ Thromb Haemost. https://doi.org/10.1111/jth.12710

258. de Agostini A, Lijnen HR, Pixley RA et al (1984) Inactivation of factor XII active fragment in normal plasma. Predominant role of C1-inhibitor. J Clin Invest 73:1542-1549. https://doi.org/10.1172/ JCI1 11360

259. Schapira M, Scott CF, Colman RW (1982) Contribution of plasma protease inhibitors to the inactivation of kallikrein in plasma. $\mathrm{J}$ Clin Invest 69:462-468. https://doi.org/10.1172/JCI1 10470

260. Stelton CR, Connors DB, Walia SS, Walia HS (2013) Hydrochloroquine retinopathy: characteristic presentation with review of screening. Clin Rheumatol 32:895-898. https://doi. org/10.1007/s10067-013-2226-2

261. Schrezenmeier E, Dörner T (2020) Mechanisms of action of hydroxychloroquine and chloroquine: implications for rheumatology. Nat Rev Rheumatol 16:155-166

262. Jang C-H, Choi J-H, Jue D-M (2006) Chloroquine inhibits production of TNF-a, IL-1b and IL-6 from lipopolysaccharidestimulated human monocytes/macrophages by different modes. Rheumatology 45:703-710. https://doi.org/10.1093/ rheumatology/kei282

263. Belisario MA, Maturo M, Avagnale G et al (1996) In vitro effect of avarone and avarol, a quinone/hydroquinone couple of marine origin, on platelet aggregation. Pharmacol Toxicol 79:300-304. https://doi.org/10.1111/j.1600-0773.1996.tb00013.x
264. Bourboulia D, Stetler-Stevenson WG (2010) Matrix metalloproteinases (MMPs) and tissue inhibitors of metalloproteinases (TIMPs): positive and negative regulators in tumor cell adhesion. Semin Cancer Biol 20:161-168

265. Lee JM, Kronbichler A, Park SJ et al (2019) Association between serum matrix metalloproteinase- (MMP-) 3 levels and systemic lupus erythematosus: a meta-analysis. Dis Markers 2019. https:// doi.org/10.1155/2019/9796735

266. Lesiak A, Narbutt J, Sysa-Jedrzejowska A et al (2010) Effect of chloroquine phosphate treatment on serum MMP-9 and TIMP-1 levels in patients with systemic lupus erythematosus. Lupus 19: 683-688. https://doi.org/10.1177/0961203309356455

267. Wozniacka A, Lesiak A, Narbutt J et al (2006) Chloroquine treatment influences proinflammatory cytokine levels in systemic lupus erythematosus patients. Lupus 15:268-275. https://doi.org/10. 1191/0961203306lu2299oa

268. Qiao F, Pan P, Yan J et al (2019) Role of tumor-derived extracellular vesicles in cancer progression and their clinical applications (review). Int J Oncol 54:1525-1533. https://doi.org/10.3892/ijo. 2019.4745

269. Leal AC, Mizurini DM, Gomes T et al (2017) Tumor-derived exosomes induce the formation of neutrophil extracellular traps: implications for the establishment of cancer-associated thrombosis. Sci Rep:7. https://doi.org/10.1038/s41598-017-06893-7

270. Prietl B, Treiber G, Pieber TR, Amrein K (2013) Vitamin D and immune function. Nutrients 5:2502-2521. https://doi.org/10. 3390/nu5072502

271. Vieth R (1999) Vitamin D supplementation, 25-hydroxyvitamin D concentrations, and safety. Am J Clin Nutr 69:842-856.https:// doi.org/10.1093/ajcn/69.5.842

272. Handono K, Sidarta YO, Pradana BA et al (2016) Vitamin D prevents endothelial damage induced by increased neutrophil extracellular traps formation in patients with systemic lupus erythematosus. Acta Med Indones 46:189-198

273. Bushra R, Aslam N (2010) An overview of clinical pharmacology of Ibuprofen. Oman Med J 25(3):155-1661. https://doi.org/10. 5001/omj.2010.49

Publisher's Note Springer Nature remains neutral with regard to jurisdictional claims in published maps and institutional affiliations. 